University of Wollongong

Research Online

Faculty of Engineering and Information

Faculty of Engineering and Information

Sciences - Papers: Part B

Sciences

2017

Mechanical properties of reactive powder concrete containing industrial and waste steel fibres at different ratios under compression

Ahmed Al-Tikrite

University of Wollongong, afs017@uowmail.edu.au

Muhammad N. S Hadi

University of Wollongong, mhadi@uow.edu.au

Follow this and additional works at: https://ro.uow.edu.au/eispapers1

Part of the Engineering Commons, and the Science and Technology Studies Commons

Research Online is the open access institutional repository for the University of Wollongong. For further information contact the UOW Library: research-pubs@uow.edu.au 


\title{
Mechanical properties of reactive powder concrete containing industrial and waste steel fibres at different ratios under compression
}

\author{
Abstract \\ This paper investigates experimentally the influence of type, content and geometry of steel fibre \\ (industrial/waste) on the mechanical properties of reactive powder concrete (RPC) in terms of \\ compressive strength, tensile strength, modulus of elasticity and stress-strain behaviour under \\ compression. Three types of steel fibres were used: industrial micro steel fibre (MF), industrial deformed \\ steel fibre (DF) and waste steel fibre recovered from discarded tyres (WF). Steel fibres were added to RPC \\ at $1 \%, 2 \%, 3 \%$ and $4 \%$ of the total volume. Two forms of steel fibres' hybridizations were explored: \\ industrial hybridization (HF) and waste-industrial hybridization (WHF). Results of testing demonstrate that \\ the addition of DF and WF up to $3 \%$ and $4 \%$, respectively, significantly affected the flowability of RPC. The \\ addition of $4 \% \mathrm{MF}$ achieved the highest increase in the compressive strength, tensile strength, modulus of \\ elasticity, peak stress and the corresponding strain. The inclusion of HF increased the RPC toughness by \\ $245 \%$. Moreover, the inclusion of the waste steel fibre as full replacement (WF) or partial replacement \\ (WHF) was comparable to the industrial steel fibre in enhancing the mechanical properties of RPC in \\ addition to the increase in the toughness of RPC by $158.8 \%$ and $211 \%$, respectively. Finally, WF is \\ considered as a promising material in the structural applications and can fully or partially replace \\ industrial steel fibres in RPC.

\section{Disciplines} \\ Engineering | Science and Technology Studies

\section{Publication Details} \\ Al-Tikrite, A. \& Hadi, M. N. S. (2017). Mechanical properties of reactive powder concrete containing \\ industrial and waste steel fibres at different ratios under compression. Construction and Building \\ Materials, 154 1024-1034.
}


Mechanical properties of reactive powder concrete containing industrial and waste steel fibres at different ratios under compression

\author{
Ahmed Al-Tikrite ${ }^{1}$ \\ ${ }^{1} \mathrm{PhD}$ Candidate, School of CME Engineering, University of Wollongong, Australia. \\ Email: afs017@uowmail.edu.au \\ Muhammad N. S. Hadi ${ }^{2}$ \\ ${ }^{2}$ Associate Professor, School of CME Engineering, University of Wollongong, Australia. \\ Email: mhadi@uow.edu.au, *Corresponding Author.
}

This paper investigates experimentally the influence of type, content and geometry of steel fibre (industrial/waste) on the mechanical properties of Reactive Powder Concrete (RPC) in terms of compressive strength, tensile strength, modulus of elasticity and stress-strain behaviour under compression. Three types of steel fibres were used: industrial micro steel fibre (MF), industrial deformed steel fibre (DF) and waste steel fibre recovered from discarded tyres (WF). Steel fibres were added to RPC at $1 \%, 2 \%, 3 \%$ and $4 \%$ of the total volume. Two forms of hybridizations were explored: industrial hybridization (HF) and waste-industrial hybridization (WHF). Results of testing demonstrate that the addition of DF and WF up to 3\% and $4 \%$, respectively, significantly affected the flowability of RPC. The addition of $4 \%$ MF achieved the highest increase in the compressive strength, tensile strength, modulus of elasticity, peak stress and the corresponding strain. The inclusion of HF increased the RPC toughness by $245 \%$. Moreover, the inclusion of the waste steel fibre as full (WF) or partial replacement (WHF) was comparable to the industrial steel fibre in enhancing the mechanical properties of RPC in addition to the increase in the toughness of RPC by $158.8 \%$ and $211 \%$, 
respectively. Finally, WF is considered as a promising material in the structural applications and can fully or partially replace industrial steel fibres in RPC.

Keywords: Reactive Powder Concrete; Micro Steel Fibre; Deformed Steel fibre; Waste Steel Fibre; Hybrid Steel Fibre; Mechanical Properties.

\section{Introduction}

Reactive powder concrete (RPC) is a special type of concrete characterised by its strength, durability and toughness. The excellent performance is attributed to the utilization of the admixtures, very fine sand and low water/binder ratio in addition to the exclusion of the coarse aggregates. The RPC is a promising construction material for civil engineering and military applications due to its superior properties. The first structure constructed from RPC in the world was Sherbrooke Bridge in Canada in 1997 [1-5]. In Turkey, the manhole covers are made of RPC [6]. However, RPC is a brittle construction material and the inclusion of steel fibre is significant to enhance the ductility of RPC. Moreover, steel fibre plays a key role in decreasing the crack initiation, spalling of the concrete cover and to increase the strength [7]. The inclusion of steel fibres in the concrete results in improving the mechanical properties of the concrete under different loading conditions $[8,9]$. Steel fibre increases the tensile and flexural strength effectively and increases the compressive strength marginally [10]. However, the size of steel fibre has an impact on the compressive strength of the concrete. For instance, Xia et al. [11] reported that short steel fibres influences the compressive strength more than long steel fibres. In addition, size of steel fibres may affect the feasibility of utilizing steel fibre in thin cross sectional structural members. Olivito et al. [12] stated that fibres' length influences the post cracking behaviour and the tensile strength while it has a little effect on the compressive strength. Also, the geometry of steel fibres has an impact on the toughness and the 
compressive strength simultaneously. Moreover, Ou et al. [13] stated that long hooked end steel fibre has a little effect on the compressive strength and modulus of elasticity of the concrete. However, the effect on the strain corresponding to the peak stress was noticeable especially when $2 \%$ were added to the mixture. Furthermore, Song and Hwang [14] reported that the inclusion of the hooked end steel fibre in the concrete significantly improves the tensile and flexural strength of the concrete when the steel fibre were added to the mixture up to $2 \%$ of the total volume. On the other hand, Nataraja et al. [15] investigated the inclusion of crimped steel fibre in the concrete and reported that the inclusion of the crimped steel fibre in the concrete increases the toughness of the concrete while it has little effect on the compressive strength. Also, these increases are proportional to the length, diameter and ratio of the steel fibre. Therefore, some researchers suggested incorporating two types of steel fibres in concrete in order to make use of the function of each steel fibre to improve the engineering properties of concrete. The incorporation of two or more types of steel fibre in the concrete is called steel fibre hybridization.

Steel fibre hybridization plays a key role in enhancing the mechanical properties of concrete. The inclusion of two or more types of steel fibre in the concrete effectively enhances the properties of the concrete as reported in previous studies. Yu et al. [16] reported that the hybridization between long and short steel fibres results in good workability and improves mechanical properties. However, long steel fibre has more influence on the behaviour of the concrete under impact loading than short steel fibre. Kang et al. [17] reported that the tensile behaviour of the Ultra-High Strength Concrete (UHSC) was noticeably improved when various types of steel fibres were included. Furthermore, Feldman and Zheng [18] investigated the hybridization of two types of fibres (polypropylene and steel fibres). Their results showed that 
the toughness and the post peak behaviour of the concrete. Banthia and Sheng [19] studied the influence of blending low modulus carbon fibres and high modulus steel fibres. Results demonstrated that steel fibres enhanced the strength of the concrete while the carbon fibres enhanced the toughness of the concrete. Therefore, the inclusion of different types of fibres has different impacts on the mechanical properties of concrete. Attempts continue to find a combination of steel fibres that achieve the maximum advantages of including steel fibres in concrete.

In addition, in recent years, several studies attempted to include waste fibres from waste materials to investigate their functionality in concrete. In addition, the inclusion of various kinds of by-products in concrete has become a widespread practice [20-22]. The utilization of the waste fibres as an alternative to the industrial steel fibre is due to its environmental and economic advantages. In particular, the incorporation of waste steel fibre recovered from waste tyres in normal strength concrete was widely explored. The outcomes were the waste steel fibres (WF) effectively improved the behaviour of normal strength concrete after the peak-load was reached and that WF is similar to the industrial steel fibre in enhancing the energy absorption, pull-out behaviour and post cracking behaviour of normal strength concrete. Also, WF is comparable to the industrial steel fibres in enhancing the properties of concrete and it is a promising material for structural applications [23-24]. Aiello et al. [23] stated that WF was similar to the industrial steel fibre in improving the flexural and post cracking behaviour of the concrete. Papakonstantinou and Tobolski [25] concluded that WF greatly increases the toughness of concrete. Also it was concluded that WF has not influenced the workability of concrete noticeably. Furthermore, Centonze et al. [26] reported that the inclusion of WF in the normal strength concrete has effectively improved the post peak behaviour of the concrete and WF is comparable to the industrial steel fibres when incorporated in the concrete. 
Accordingly, this paper investigates experimentally the mechanical properties (compressive strength, tensile strength and stress-strain behaviour and modulus of elasticity) of RPC that includes different types of steel fibres at different amounts under compression. Industrial micro steel fibre (MF), deformed steel fibres (DF) and waste steel fibre (WF) were utilized at $1 \%$, $2 \%, 3 \%$ and $4 \%$. Also, this paper explores the influence of steel fibre hybridization on the mechanical properties of the RPC. Two proportions of hybridization were used based on the optimum ratio of steel fibre to be added to the RPC that were experimentally obtained in this study. Industrial steel fibre hybridization (HF) includes the hybridization between $50 \%$ of the optimum ratio of each MF and DF (2\% MF and 1\% DF) which forms 3\% of the total volume of the mixture. Waste-industrial steel fibres hybridization (WHF) includes replacing $50 \%$ of $\mathrm{HF}$ with WF by blending $50 \%$ of the optimum ratio of WF and $25 \%$ of the optimum ratio of each MF and DF (1.5\% WF, $1 \% \mathrm{MF}$ and $0.5 \% \mathrm{DF})$ to form $3 \%$ of the total volume of the RPC mixture. The conventional casting and curing methods were used in this study.

\section{Experimental Investigation}

\subsection{Materials and proportions}

General purpose cement [27] was used in this study at $955 \mathrm{~kg} / \mathrm{m}^{3}$. The silica fume utilized was amorphous high grade densified silica fume powder [28] at $229 \mathrm{~kg} / \mathrm{m}^{3}$. The chemical composition of the cement and the silica fume are shown in Table 1 and Table 2. The fine sand was from local natural resources and sieved to a size less than $600 \mu \mathrm{m}$. The specific gravity of the sand was 2.65 and the proportion in RPC was $974 \mathrm{~kg} / \mathrm{m}^{3}$. Silica flour of a grade 200 was utilized at $10 \mathrm{~kg} / \mathrm{m}^{3}$. The water reducer and retarder (superplasticiser) was used at $52.6 \mathrm{~L} / \mathrm{m}^{3}$. Three different types of steel fibres were utilized. Micro steel fibre (MF) of $6 \mathrm{~mm}$ in length, 0.2 $\mathrm{mm}$ diameter and $2500 \mathrm{MPa}$ tensile strength [29]. Deformed steel fibre (DF) of $18 \mathrm{~mm}$ in length, $0.55 \mathrm{~mm}$ diameter and $800 \mathrm{MPa}$ the tensile strength [30]. Waste steel fibres recovered 
from waste tyres (WF) were utilized from a local source. The dimensions of WF were measured by using the following procedure:

127

Ten groups of WF were selected randomly. Each group contained one hundred fibres. The diameter and length of the fibres were measured by a micrometre. Four measurements were taken for each fibre, two diameter measurements at each end, one diameter measurement in the middle and one length measurement. Based on the measurements, the ranges of diameters and lengths and the percentage of each range of WF utilized are shown in Fig. 1 (a) and (b), respectively. Types of steel fibres used are shown in Fig. 2. The volume fraction of each steel fibre was $1 \%, 2 \% 3 \%$ and $4 \%$. The water/binder ratio was 0.133 . The mixture utilized in this study is based on a proposed mixture by Richard and Cheyrezy [5] and modified to maintain the flowability within the allowable limits. procedure proposed by Bonneau et al. [31]. Some amendments were performed in order to suit the mixed constituents. The mixing process was performed by mixing the dry materials first (cement, silica fume, silica flour and the natural river sand) in the vertical mixer's pan shown in $20 \%$ water and $50 \%$ superplasticiser were next added to the mixture in the mixer's pan. The mixing process continued for about five minutes until the mixture particles started to form flocks. The $1 \%$ volume fraction of steel fibre was added to the mixture and the mixing process continued for about 4 minutes until the mixture became flowable. The addition of steel fibre 
was in multiples of $1 \%$ until the total of additions of the steel fibre reached $4 \%$. After each

151

152

153

154

155

156

157

158

159

addition of steel fibres, six cylinders $100 \mathrm{~mm}$ in diameter and $200 \mathrm{~mm}$ in height were cast for compressive and indirect tensile strength tests and three cylinders $150 \mathrm{~mm}$ in diameter and 300 $\mathrm{mm}$ in height were cast for stress-strain test in line with the past studies [12-14, 31-38]. Casting and curing of the specimens were performed according to the Australian Standards AS 1012.8.1 [39].

Six sets of RPC mixtures were cast and labelled according to the steel fibre included as follows: the reference specimens which are non-fibrous (NF), Micro steel fibre (MF), Deformed steel fibre (DF), Waste steel fibre (WF), Hybrid industrial steel fibre (HF) and Hybrid waste-industrial steel fibre (WHF). Each set of the MF, DF and WF includes four groups of RPC containing 1\%, 2\%, 3\% and $4 \%$ of steel fibre. These groups were prepared and named based on the type and the proportion of fibres. For example, MF1 represents the RPC mix with $1 \%$ micro steel fibre and WF2 represents the RPC with $2 \%$ waste steel fibre. The hybrid steel fibres sets HF and WHF include 3\% steel fibres and were labelled as HF and WHF, respectively. Before casting, flowability test was conducted to investigate the influence of steel fibres inclusion on the flowability of RPC. Table 3 shows the experimental test matrix of the current study.

In total, 15 mixtures were cast, 90 cylinders $100 \mathrm{~mm}$ in diameter and $200 \mathrm{~mm}$ in length and 45 cylinders $150 \mathrm{~mm}$ in diameter and $300 \mathrm{~mm}$ in length were prepared. The repeatability of these mixes was verified by conducting several trial mixes before embarking on the current experimental investigation. After casting, the specimens remained in the moulds for about 24 hours at the laboratory, then; the specimens were demoulded and placed in a curing water tank at $20^{\circ} \mathrm{C}$ for further 27 days. After that, the specimens were removed from the water tank and 
left to dry. For testing, the specimens were capped with high strength plaster to get level surface as shown in Fig. 4. Finally, the specimens were tested under compression and indirect tension.

\section{Results and Discussion}

\subsection{Flowability}

Flowability test was conducted according to ASTM C 230/C 230M [40] to investigate the influence of steel fibres inclusion on the flowability of RPC. Fig. 5 shows the flowability testing apparatus used for this test. It was noticed that the addition of steel fibres affected the flowability of RPC. Fig. 6 shows the influence of steel fibres content and geometry on flowability of fresh mixture of RPC. The addition of MF at 1\%,2\%,3\% and $4 \%$ decreased flowability of RPC by $2.8 \%, 5.2 \%, 9.0 \%$ and $13.7 \%$, respectively. The reduction in the flowability could be attributed to the random dispersion of steel fibres through fresh concrete matrix and to the increased specific surface area after the addition of steel fibres [41, 42].

The geometry of the steel fibres has influenced the flowability of RPC. The addition of DF at $1 \%, 2 \%, 3 \%$ and $4 \%$ decreased the flowability by $6.6 \%, 9.9 \%, 16.0 \%$ and $28.3 \%$, respectively. This is because of the increased friction between deformed steel fibres and the matrix [42, 43]. The irregular shape of steel fibres also influences the flowability of RPC. The addition of WF to RPC at $1 \%, 2 \%, 3 \%$ and $4 \%$ decreased the flowability by $7.1 \%, 12.3 \%, 16.5 \%$ and $33.5 \%$, respectively. Moreover, the inclusion of $\mathrm{HF}$ and WHF at 3\% decreased the flowability of RPC by $13.2 \%$ and $14.6 \%$, respectively. It is obvious that the reduction in flowability of RPC includes DF (DF-RPC) and WF (WF-RPC) is higher than the reduction in flowability of RPC includes MF (MF-RPC). This could be due to steel fibres geometry and shape which makes steel fibre tends to bundle between them [41]. 


\subsection{Compressive strength}

201 The compressive strength tests were conducted according to the Australian Standards AS 1012.9 [44]. The average of three cylinders $100 \mathrm{~mm}$ in diameter and $200 \mathrm{~mm}$ in height were

203 tested under compression is taken as the nominal compressive strength of RPC. This test was done by using Avery compression testing machine of $1800 \mathrm{kN}$ loading capacity (see Fig. 7). The experimental results are shown in Table 4. The compressive strength of the plain RPC experimentally obtained was $100.2 \mathrm{MPa}$. The addition of $1 \%, 2 \% 3 \%$ and $4 \%$ of MF, DF and WF individually have increased the compressive strength noticeably for RPC specimens that include MF and WF while the increase in compressive strength was marginal for the RPC specimens that included DF compared to NF Specimens (reference). The addition of MF at 1\%, $2 \% 3 \%$ and $4 \%$, increased the compressive strength by $11.8 \%, 20.4 \%, 21.3 \%$ and $34.0 \%$, respectively. The addition of DF has increased the compressive strength of the RPC by $0.4 \%$, $2.2 \%, 0.4 \%$ and $0.1 \%$ when $1 \%, 2 \% 3 \%$ and $4 \%$ DF were added to the RPC mixture, respectively. On the other hand, the addition of WF to RPC has achieved an increase in the compressive strength compared to NF by $9.9 \%, 15.6 \%, 21.0 \%$ and $10.6 \%$ when WF were added to the RPC mixture at $1 \%, 2 \% 3 \%$ and $4 \%$, respectively. In general the increase in the compressive strength with the addition of the steel fibre compared to the reference is attributed to the role of the steel fibre in bridging cracks which prevent the initiation and propagation of cracks, leading to increasing the load carrying capacity of the concrete and inhibiting the disintegration of the concrete, simultaneously $[45,46]$. Also, the decrease in the compressive strength of $\mathrm{WF}$ at $4 \%$ and $\mathrm{DF}$ at $3 \%$ and $4 \%$ could be attributed to the uneven distribution of fibres in the mixtures [47].

The hybridization of the steel fibres played a key role in improving the compressive strength of RPC. The inclusion of the industrial hybrid steel fibres (HF) has increased the compressive 
strength by $25.1 \%$ compared to NF while the addition of the waste/industrial steel fibres hybridization (WHF) has increased the compressive strength by $24.5 \%$ in comparison with NF. The increase in compressive strength achieved at the addition of HF is relatively higher than that when WHF was added compared to NF. This could be attributed to the uniform distribution of the industrial steel fibre in the RPC mixture when HF was used. However, the addition of WF whether it was added individually or in hybrid form has influenced the compressive strength of RPC positively by achieving increases comparable to the industrial counterparts when added to RPC. The Addition of WF also saves the cost of the industrial steel fibres and results in comparable properties of the fibrous RPC specimens.

In summary, the addition of MF, DF, WF, HF and WHF to the plain RPC has shown an improvement in the compressive strength of the RPC and that the steel fibre acts as reinforcement in the concrete. The good bond with the cement paste and the control of crack initiation inside the concrete assists to resist the applied loads and thus increases the strength of the concrete. In particular, the addition of MF has attained the highest compressive strength compared to the WF and DF. However, the performance of WF in RPC is comparable to MF in increasing the strength. These results agree with previous studies conducted on fibrous concrete. Yusof et al. [48] stated that short steel fibre influences the compressive strength more than the long steel fibres do. Fig. 8 shows the compressive strength of RPC that include MF, DF, WF, HF and WHF.

The failure of specimens started by the appearance of vertical micro hairline cracks at the midheight of specimens when reaching the compressive strength. Afterwards, hairline cracks started to spread and the width of the cracks started to extend after reaching the compressive strength. The sound of ticking which refers to the pull out of steel fibres that bridge the cracks 
from the concrete was heard. However, the plain RPC after reaching the compressive strength failed suddenly in an explosive way with a loud sound of smashing. For MF specimens, the typical failure was by the extension of the vertical cracks along the specimen. For DF specimens, the typical failure occurred at the mid-height in the vertical and horizontal directions accompanied by scattered spalling of concrete. The typical failure of HF specimens occurred by the appearance of vertical cracks that extended along the length of the specimen without the appearance of scattered cracks. However, the typical failure of WF specimens occurred at the mid-height only while the ends have been slightly affected by the compressive loading until failure unlike its counterparts. The typical failure of WHF specimens occurred by the appearance of a line crack that extended from the top to the mid-height of specimen in the vertical and horizontal directions without scattered cracks along the specimen. That crack spread in a line in the horizontal direction then in the vertical direction without spreading into forked crack. Fig. 9 shows the typical failure of the tested specimens.

It is worth mentioning that the fibrous RPC specimens tested under compression did not split into two pieces as the plain RPC specimens did under compression. The tested fibrous RPC specimens remained connected in one piece due to the bridging cracks action of the steel fibre which maintained the specimens in one piece as shown in Fig. 9.

\subsection{Tensile strength}

The tensile strength tests were conducted according to the Australian Standards AS 1012.10 [49]. The average of three cylinders $100 \mathrm{~mm}$ in diameter and $200 \mathrm{~mm}$ in height tested under indirect tension is taken as the tensile strength of RPC. This test was done by using Avery compression testing machine of $1800 \mathrm{kN}$ loading capacity. Fig. 10 shows Specimen DF1 under indirect tension. The tensile strength results show that the plain RPC Specimens (NF) can 
withstand an indirect tensile strength of $10.3 \mathrm{MPa}$. The NF Specimens were split into two pieces beyond the ultimate tensile strength (at failure). The addition of MF at $1 \%, 2 \%, 3 \%$ and $4 \%$ has increased the tensile strength by about $49.1 \%, 77.9 \%, 112.3 \%$ and $141.4 \%$, respectively, compared to NF. The addition of DF at $1 \%, 2 \%, 3 \%$ and $4 \%$ increased the tensile strength by $14.3 \%, 37.5 \%, 11.1 \%$ and $3.2 \%$, respectively. The addition of WF has achieved increases in the tensile strength of RPC by $48.4 \%, 69.3 \%, 125.0 \%$ and $58.5 \%$ when $1 \%, 2 \%$, $3 \%$ and $4 \%$ of WF were added to RPC, respectively. The increases in the tensile strength of the WF Specimens are comparable to the increases achieved in the tensile strength. This might be attributed to the good bond between WF and the matrix due to the diversity of the shape and the geometry of the waste steel fibres.

The hybridization has an effect on the tensile strength of RPC. The addition of $3 \% \mathrm{HF}$ increased the tensile strength of RPC from 10.3 MPa for NF Specimens to 19.7 MPa for HF Specimens. Furthermore, the addition of $3 \%$ WHF increased the tensile strength of RPC from 10.3 MPa for NF Specimens to 19.4 MPa. The increases achieved in tensile strength when HF and WHF were added are $91.6 \%$ and $88.4 \%$, respectively. The differential increase in the tensile strength between HF and WHF Specimens is marginal and the interaction between MF, DF and WF in improving the RPC properties is functional. The addition of WF individually has enhanced the tensile strength of RPC noticeably. The addition of WF in a hybrid form with MF and DF reduced the industrial steel fibres quantity included and achieved similar tensile strength. Fig. 11 shows the tensile strength of RPC that included MF, DF, WF, HF and WHF.

Previous studies conducted on the fibrous concrete concluded that the addition of fibres to the concrete results in an increase in the tensile strengths of the concrete noticeably [14, 50-51]. 


\subsection{Stress-strain behaviour}

301

302

303

304

305

306

307

308

309

310

311

312

313

314

315

316

317

318

319

320

321

324

\subsubsection{Peak stress and corresponding strain}

This test was performed according to AS 1012.17 [52] on the RPC specimens $150 \mathrm{~mm}$ in diameter and $300 \mathrm{~mm}$ in height tested under compression at a constant strain rate. The size of specimens was used according to the available deformation measuring apparatus in the laboratory which was designed according to AS 1545 [53] to fit that size and comply with AS 1012.08.1 [39]. Three Linear Variable Differential Transformer (LVDTs) were used to record the data. The stress-strain curves for RPC with/without steel fibres are shown in Fig. 13 (a-e). Fig. 12 shows Specimen WF3 under compression. Based on the tested specimens, it is obvious that RPC is very brittle and fails suddenly under compression without prior signs of failure. Also, the steel fibres effectively enhanced the resistance of RPC to applied loads by increasing the peak stress that the concrete can withstand and prevented the sudden failure in addition to the post peak behaviour enhancement of RPC.

Firstly, the addition of the steel fibres influenced the post peak behaviour of RPC. Type, quantity and geometrical shape of the steel fibre have an impact on the behaviour of RPC. The addition of MF, DF and WF effectively increased the peak stress of the plain RPC (NF). The addition of MF at $4 \%$ achieved the highest peak stress of $128.1 \mathrm{MPa}$ compared to DF, WF, HF and WHF specimens. The addition of $2 \%$ DF increased the peak stress by $1.4 \%$ to get to 98.3 MPa. The addition of WF at $3 \%$ has gained an increase of $20.8 \%$ to get to $117.1 \mathrm{MPa}$ which is higher than the peak stress of WF1, WF2 and WF4. Both hybridizations of steel fibres HF and WHF at $3 \%$ increased the peak stress by $28.1 \%$ and $27.8 \%$, respectively. The WHF hybridization resulted in a good performance compared to the HF hybridization in addition to the fact that WF has replaced $50 \%$ of the industrial steel fibres which reflects economical and environmental advantages. 
The inclusion of steel fibres has influenced positively the strain corresponding to the peak stress of RPC. The addition of MF, DF, WF, HF and WHF increased the strain corresponding to the peak stress noticeably. Increasing the content of the steel fibre to some extent plays a key role in increasing the strain corresponding to the peak stress (see Table 5). To explore the improvement in the strain corresponding to the peak stress, the RPC specimens that included $\mathrm{MF}, \mathrm{DF}, \mathrm{WF}, \mathrm{HF}$ and WHF are compared to NF specimens to measure the range of the improvement. The strain corresponding to the peak stress of RPC including MF at 1\%, 2\%, 3\% and $4 \%$ was increased by $5.5 \%, 14.5 \%, 19.7 \%$ and $29.4 \%$, respectively. The addition of DF at $1 \%, 2 \%, 3 \%$ and $4 \%$ increased the strain at peak stress by $0.3 \%, 2.1 \%, 0.8 \%$ and $0.4 \%$, respectively. The addition of $\mathrm{HF}$ attained the highest increase in the strain corresponding to the peak stress by $33.4 \%$ at $3 \%$ addition of HF compared to NF.

The inclusion of WF at $1 \%, 2 \%, 3 \%$ and $4 \%$ increased the strain corresponding to the peak stress by $13.3 \%, 14.4 \%, 22.6 \%$ and $10.5 \%$, respectively. The hybridization between WF and $\mathrm{MF}$ and DF at 3\% increased the strain of RPC by $25.9 \%$. It is obvious that the addition of steel fibres enhanced the deformability resistance of RPC by increasing the strain at the peak stress 2.1\%-33.4\%. Furthermore, the hybridization between the MF, DF and WF has enhanced the peak stress and the corresponding strain efficiently and the improvement to the RPC peak stress and strain was comparable to HF hybridization in addition to the fact that WF which is a waste material has replaced $50 \%$ of the industrial steel fibre and resulted in comparable enhancement.

The increase in the peak stress of the tested specimens resulted in an increase in the corresponding strain. The addition of MF up to $4 \%$ resulted in $7 \%$ average increase in the peak compressive stress and the corresponding strain after each addition of MF, respectively. Also, 
the average increase in the peak compressive stress and the corresponding strain when WF were added up to $3 \%$ is $7 \%$, respectively. The addition of DF up to $2 \%$ achieved a slight average increase in the peak compressive stress and the corresponding strain about $1 \%$, respectively. Moreover, the hybridization of steel fibres resulted in an increase in the peak compressive stress and the corresponding strain. However, the increase was varied upon the steel fibre types that formed the hybrid steel fibre. The influence of steel fibre hybridization is more obvious when HF was added compared to WHF. The strain corresponding to the peak compressive stress of HF is $6 \%$ higher than the strain corresponding to peak compressive stress of WHF.

\subsubsection{Toughness and Toughness Index}

In this study, the area under the stress-strain curve is considered as the toughness of the concrete $[15,54]$. For the plain RPC, the whole area under the stress-strain curve is considered to calculate the toughness. For the RPC specimens containing steel fibres, the area under the stress-strain curve up to a strain equal to 0.006 is considered to calculate the toughness. Toughness Index (TI) was calculated to explore the improvement in the toughness of RPC reinforced with different types of steel fibre under compression. The Toughness index $(T I)$ is defined as [54]:

$$
T I=T_{S F} / T_{N F}
$$

where, $T_{S F}$ is the toughness of the steel fibre reinforced RPC, $T_{N F}$ is the toughness of nonfibrous RPC (NF). The results of the toughness and toughness index are presented in Table 5.

From the results obtained, RPC fails in a brittle manner under compression. The addition of steel fibres to the plain RPC improved the toughness of RPC through increasing the area of the stress-strain curve due to the increased peak stress, corresponding strain and the post peak 
curve softening. The addition of steel fibres resulted in more flattened curve after the peak stress was reached. However, the descending branch of the curve after the peak stress had a different slope at each addition of the steel fibres. Increasing the steel fibres content to some extent results in the descending branch of the curve after the peak stress to become more flattened as shown in Fig. 13 (a)-(e) and thus, increasing the toughness of RPC.

The typical toughness of NF was $0.133 \mathrm{MPa}$. The addition of MF increased the toughness by $29.8 \%, 116.8 \%, 153.6 \%$ and $249.8 \%$ when MF was added to RPC at $1 \%, 2 \%, 3 \%$ and $4 \%$, respectively. The Toughness Index $(T I)$ was increased with the increase in the MF content and the highest typical TI obtained was 3.5 at the addition of $4 \%$ MF (MF4). This could be attributed to the uniform distribution of MF throughout the whole matrix without entangling between them as the length of MF is very short. Consequently, the initiation and propagation of the micro cracks were inhibited through the bridging action of MF. The addition of DF to the plain RPC at $1 \%$ and $2 \%$ (DF1 and DF2) increased the toughness by $65.4 \%, 97.6 \%$, respectively, compared to NF. The typical $T I$ has increased from 1 for NF to 1.7 and 2.0 at the addition of DF at $1 \%$ and $2 \%$, respectively. Increasing the DF content to $3 \%$ and $4 \%$ resulted in the typical toughness of DF3 and DF4 to decrease by $42.9 \%$ and $43.6 \%$, respectively, compared to DF2. The typical TI was decreased from 2.0 to 1.1 in comparison with DF2. The behaviour of the specimens of Groups DF3 and DF4 were brittle and did not show a ductile behaviour like the specimen of Groups DF1 and DF2. This could be attributed to the irregular dispersion of DF in high volume fractions inside the concrete paste [47].

The hybridization between MF and DF resulted in improvement in the toughness of RPC. The addition of $\mathrm{HF}$ at $3 \%$ effectively improved the typical toughness by $245.7 \%$ compared to NF and achieved a typical toughness of 0.46 compared to the typical toughness of NF which is 

the interaction between MF and DF which were distributed randomly throughout the matrix that restrained the crack initiation and propagation. The MF restrains the initiation of the micro cracks while DF bridging the macro cracks and resists crack widening via pull out from concrete. On the other hand, the addition of WF at $1 \%, 2 \%, 3 \%$ and $4 \%$ increased the typical toughness of RPC by $119.3 \%, 115.8 \%, 158.8 \%$ and $118.2 \%$, respectively, compared to NF. Also, the typical $T I$ was increased from 1.0 for NF to 2.2, 2.2, 2.6 and 2.2 for WF1, WF2, WF3 and WF4, respectively. The increase in the typical toughness achieved for WF4 is less than the typical toughness achieved for WF3. This is attributed to the non-uniform distribution of WF throughout the RPC matrix and also the lack of compactness of the RPC due to the high amounts of WF included [33]. Furthermore, the hybridization between WF, MF and DF at 3\% (WHF) resulted in an increase in the typical toughness of WHF by $211.1 \%$ compared to NF and achieved a typical toughness of 0.41 . This is due to the contribution of the short and long in preventing the initiation of the micro cracks, the propagation of the cracks and restraining the macro cracks to be widened.

It is clear that the addition of WF to RPC individually or in hybrid form effectively improved the toughness and the Toughness Index which indicates a decrease in the brittle behaviour of the RPC. Also, the addition of WF has achieved a considerable enhancement in the toughness of RPC which is comparable to the enhancement that was achieved by the addition of MF, DF and HF. As a matter of fact, the addition of WF to the RPC individually or in hybrid form saves the cost for $50 \%$ to $100 \%$ of steel fibre in addition to the environmental advantages represented by the recycling of the waste materials (discarded tyres) which is considered as the main environmental polluter. The influence of each steel fibre on the toughness and strength of the RPC when added individually or in hybrid form is shown in Fig. 14. It is clear that the addition 
of MF at $1 \%, 2 \%, 3 \%$ and $4 \%$ greatly influenced the strength and toughness of RPC. However, the inclusion of WF up to $3 \%$ has more influence on the strength and toughness of RPC than MF up to $3 \%$. Furthermore, the slope of trend line of HF is sharp which represents that HF steel fibre influences the toughness of RPC more than the strength while the slope of the trend line of WHF is less sharp compared with HF which indicates a balanced influence of WHF steel fibres on the toughness and strength of RPC.

The findings in this study are in line with the previous studies in regards to steel fibres inclusion in concrete. Gopalaratnam and Shah [55] concluded that the inclusion of the steel fibre in the brittle construction material improves the toughness, resistance to crack propagation and increases the tensile strength. Yao et al. [51] concluded that the addition of fibres to the concrete effectively improves the toughness of the concrete.

\subsection{Modulus of elasticity}

The modulus of elasticity is obtained by determining the slope of a tangent of the stress-strain curve that meets the curve at the point of origin according to ACI 318-11 [56] by drawing a tangent to the stress -strain curve that meets the curve at the origin and passes through a stress equal to $45 \%$ of the peak stress. The slope of the tangent represents the modulus of elasticity of the concrete. Table 4 shows the modulus of elasticity values of the tested specimens. It is observed that the value of the modulus of elasticity was increased with the increase in the steel fibre content. In comparison with modulus of elasticity of the reference specimen (NF), the addition of $1 \%, 2 \%, 3 \%$ and $4 \%$ of MF increased the average modulus of elasticity by $7.2 \%$, $8.4 \%, 13.3 \%$ and $18.7 \%$, respectively. Furthermore, the addition of DF at $1 \%, 2 \%, 3 \%$ and $4 \%$ 
hybridization between MF and DF at 3\% HF achieved an increase in the average modulus of elasticity of RPC by $12.5 \%$.

The inclusion of WF in the RPC at $1 \%, 2 \%, 3 \%$ and $4 \%$ increased the average modulus of elasticity by $3.1 \%, 9.2 \%, 13.0 \%$ and $8.7 \%$, respectively, in comparison with modulus of elasticity of NF. The addition of WHF at $3 \%$ resulted in an increase in the average modulus of elasticity by $13.9 \%$. It is obvious that the higher increases in the modulus of elasticity of RPC were achieved at the addition of MF and this is due to the high increase in the strength of RPC as a result of the utilization of MF which influences the strength of the concrete effectively. The industrial hybridization of MF and DF at 3\% (2\% MF and 1\% DF) reduced the quantity of fibres utilized by $1 \%$ compared to MF4 and achieved an increase in the average modulus of elasticity by $12.5 \%$ in comparison with the NF specimens. Furthermore, the addition of WF at $3 \%$ has achieved an increase in the average modulus of elasticity of WF3 by $13 \%$ which is comparable to the increase in the average modulus of elasticity of MF4 (13.3\%). In addition, the hybridization between WF, DF and MF has achieved an increase in the average modulus of elasticity by $13.9 \%$ which is $1.4 \%$ higher than the increase in the modulus of elasticity when HF was added.

It was noticed that the increase in the average modulus of elasticity of RPC specimens met by an increase in the average compressive strength. When $4 \% \mathrm{MF}$ was added, the increases in the average compressive strengths and modulus of elasticity were $8 \%$ and $4 \%$, respectively. Also, when WF was added up to $3 \%$, the increases in the average compressive strength and modulus of elasticity were $7 \%$ and $4 \%$, respectively. The increases in the average compressive strength and modulus of elasticity of RPC that included DF up to $2 \%$ were $1 \%$ and $3 \%$, respectively. Fig. 15 shows the average modulus of elasticity versus the average compressive strength of the 
474 tested RPC specimens. The average ratio of the increases in the compressive strength to the 475 modulus of elasticity of RPC that included MF up to $4 \%$, DF up to $2 \%$ and WF up to $3 \%$ was

$4761.8,0.3$ and 2.2, respectively. For $\mathrm{HF}$ and WHF, the average ratio of the increase in the 477 compressive strength to the modulus of elasticity of RPC that included HF and WHF was 2.0 478 and 1.8, respectively. Fig. 16 shows the rate of increase in the compressive strength to the 479 modulus of elasticity RPC specimens that included MF, DF, WF, HF and WHF at 4\%, 2\%, 3\%, 480 $3 \%$ and $3 \%$, respectively.

In general, the inclusion of steel fibres in RPC positively improved the modulus of elasticity noticeably. This is due to the positive influence of the steel fibres on the strength of RPC. The results obtained in this study is consistent with the past studies [36, 57-59] which were conducted on the steel fibre incorporated in the concrete which concluded that the inclusion of steel fibres in the concrete increases the modulus of elasticity of the concrete noticeably.

\section{Conclusions}

Based on the experimental results obtained, the following conclusion could be withdrawn as 490 follows:

1. The flowability of RPC was affected to some extent when a certain content of steel fibres were added. The inclusion of MF, WF and DF in RPC up to 4\%, 3\% and 2\%, respectively, has a little effect on the flowability of RPC matrix. However, increasing the WF and DF volume content up to $4 \%$ and $3 \%$, respectively, completely affected the flowability of RPC and resulted in less workable concrete. More efforts for casting and placing in the moulds were needed due to balling phenomena which the steel fibres clamp together and restrain the matrix to flow. Therefore, the addition of WF to RPC up to $3 \%$ is feasible without further efforts. 
2. The addition of $4 \% \mathrm{MF}, 2 \% \mathrm{DF}$ and $3 \% \mathrm{WF}$ effectively increased the compressive strength, tensile strength and the modulus of elasticity of the RPC. Also, the addition of HF and WHF at 3\% considerably increased the compressive strength, tensile strength and the modulus of elasticity of the RPC.

3. The stress-strain curves were noticeably improved with the addition of the steel fibres up to a certain volume content. The shape of the stress-strain curve and the area under the stress-strain curve was increased due to the softening of the descending branch of the stress-strain curve. However, the addition of DF until $2 \%$ slightly improved the post peak behaviour of RPC while increasing the volume of DF to $3 \%$ and $4 \%$ did not exhibit a ductile behaviour.

4. The toughness was increased with the increase in the volume content of steel fibres in the RPC. The additions of $4 \% \mathrm{MF}$ and $3 \% \mathrm{WF}$ individually have achieved an increase in the typical toughness of the RPC by $249.8 \%$ and $158.8 \%$, respectively, compared to the reference (NF). The addition of DF at $2 \%$ increased the typical toughness of RPC by 97.6\%. Also, the inclusion of HF and WHF steel fibres has improved the typical toughness of RPC by $245.7 \%$ and $211.1 \%$, respectively.

5. The addition of $4 \% \mathrm{MF}$ and $3 \% \mathrm{WF}$ and $2 \% \mathrm{DF}$ to the plain RPC attained the highest typical TI compared to their counterparts. The hybridization between the MF and DF to produce $\mathrm{HF}$ and the hybridization between the industrial steel fibres $\mathrm{HF}$ and the waste steel fibre WF to produce WHF has enhanced the toughness effectively and attained higher typical TI compared to MF, DF and WF.

Based on the experimental work results, the optimum ratio of steel fibres to be added to the RPC is $4 \%$ for MF, $2 \%$ for DF and $3 \%$ for WF, HF and WHF, respectively. Also, WF can fully or partially replace the industrial steel fibre or hybridized with it effectively. 
The authors acknowledge the help of Fibercon Australia for providing the deformed steel

Fernando Escribano at the laboratory of CME in Wollongong University for providing him with help. The first author expresses his gratitude to the Iraqi Government and Wollongong University for the support of his full PhD scholarship.

530

\section{References}

532

[1] P. Aitcin, Concrete the most widely used construction materials, ACl Special Publication 154 (1995) 257-266.

534 [2] C.V. Li, C. Y. W., Determination of interfacial debond mode for fiber-reinforced cementitious composites, Journal of Engineering Mechanics 120(4) (1994) 707-719.

536 [3] S. Collepardi, L. Coppola, R. Troli, M. Collepardi, Mechanical properties of modified reactive powder concrete, ACI Special Publications 173 (1997) 1-22.

[4] V. Matte, M. Moranville, Durability of reactive powder composites: influence of silica fume on the leaching properties of very low water/binder pastes, Cement and Concrete Composites 21(1) (1999) 19.

541 [5] P. Richard, M.H. Cheyrezy, Reactive powder concretes with high ductility and 200-800 MPa compressive strength, Special Publication 144 (1994) 507-518.

543 [6] M. Canbaz, The effect of high temperature on reactive powder concrete, Construction and Building 544 Materials 70 (2014) 508-513.

545 [7] Z. Yunsheng, S. Wei, L. Sifeng, J. Chujie, L. Jianzhong, Preparation of C200 green reactive powder 546 concrete and its static-dynamic behaviors, Cement and Concrete Composites 30(9) (2008) 831-838.

547 [8] P. Shafigh, H. Mahmud, M.Z. Jumaat, Effect of steel fiber on the mechanical properties of oil palm 548 shell lightweight concrete, Materials and Design 32(7) (2011) 3926-3932.

549 [9] Y.S. Tai, Flat ended projectile penetrating ultra-high strength concrete plate target, Theoretical and 550 Applied Fracture Mechanics 51(2) (2009) 117-128.

551 [10] J. Gao, W. Sun, K. Morino, Mechanical properties of steel fiber-reinforced, high-strength, 552 lightweight concrete, Cement and Concrete Composites 19(4) (1997) 307-313.

553 [11] H. Xia, W. Wang, Z. Shi, Mechanical properties of reactive powder concrete with ultra-short brass554 coated steel fibres, Magazine of Concrete Research 67(6) (2015) 308-316. 
[12] R. Olivito, F. Zuccarello, An experimental study on the tensile strength of steel fiber reinforced concrete, Composites Part B: Engineering 41(3) (2010) 246-255.

557 [13] Y. Ou, M. Tsai, K. Liu, K. Chang, Compressive behavior of steel-fiber-reinforced concrete with a 558 high reinforcing index, Journal of Materials in Civil Engineering 24(2) (2011) 207-215.

[14] P.S. Song, S. Hwang, Mechanical properties of high-strength steel fiber-reinforced concrete, Construction and Building Materials 18(9) (2004) 669-673.

[15] M.C. Nataraja, N. Dhang, A.P. Gupta, Stress-strain curves for steel-fiber reinforced concrete under compression, Cement and Concrete Composites 21(5-6) (1999) 383-390.

[16] R. Yu, P. Spiesz, H. Brouwers, Static properties and impact resistance of a green Ultra-High Performance Hybrid Fibre Reinforced Concrete (UHPHFRC): experiments and modeling, Construction and Building Materials 68 (2014) 158-171.

[17] S. T. Kang, J. I. Choi, K. T. Koh, K.S. Lee, B.Y. Lee, Hybrid effects of steel fiber and microfiber on the tensile behavior of ultra-high performance concrete, Composite Structures 145 (2016) 37-42.

[18] D. Feldman, Z. Zheng, Synthetic fibres for fibre concrete composites, MRS Proceedings, Cambridge Univ Press, 1993, p. 123.

[19] N. Banthia, J. Sheng, Micro-reinforced cementitious materials, MRS Proceedings, Cambridge Univ Press, 1990, p. 25.

[20] B. Li, W. Liang, Z. He, Study on high-strength composite portland cement with a larger amount of industrial wastes, Cement and Concrete Research 32(8) (2002) 1341-1344.

[21] T.R. Naik, R.N. Kraus, Y.-m. Chun, B.W. Ramme, S.S. Singh, Properties of field manufactured castconcrete products utilizing recycled materials, Journal of materials in civil engineering 15(4) (2003) 400-407.

[22] T.R. Naik, Y.-M. Chun, R.N. Kraus, B.W. Ramme, R. Siddique, Precast concrete products using industrial by-products, Materials Journal 101(3) (2004) 199-206.

[23] M.A. Aiello, F. Leuzzi, G. Centonze, A. Maffezzoli, Use of steel fibres recovered from waste tyres as reinforcement in concrete: pull-out behaviour, compressive and flexural strength, Waste management 29(6) (2009) 1960-1970.

[24] K. Neocleous, K. Pilakoutas, P. Waldron, From used tyres to concrete fibre reinforcement, Proceedings of the 2nd FIB Congress, 2006.

[25] C.G. Papakonstantinou, M.J. Tobolski, Use of waste tire steel beads in Portland cement concrete, Cement and Concrete Research 36(9) (2006) 1686-1691.

[26] G. Centonze, M. Leone, M. Aiello, Steel fibers from waste tires as reinforcement in concrete: a mechanical characterization, Construction and Building Materials 36 (2012) 46-57.

[27] Cement of Australia, Safety data sheet <http://www.cementaustralia.com.au/>, 2016 (accessed 22 May.2016). 
590 [28] Synergy Pigments Australia, Safety data sheet <http://www.oxide.com.au/>, 2016 (accessed 22 591 May.2016).

592 [29] GanZhou Daye Metalic Fibres Company Ltd., <http://www.gzdymf.com/index_en.html>, 2016 593 (accessed 16 February. 2017).

594 [30] Fibercon Australia, Safety data sheet <http://www.oxide.com.au/>, 2016 (accessed 21 May.2016).

595 [31] O. Bonneau, M. Lachemi, É. Dallaire, J. Dugat, P.-C. Aïtcin, Mechanical properties and durability of 596 two industrial reactive powder concretes, ACI Materials journal 94(4) (1997) 286-290.

597 [32] E. Martinelli, A. Caggiano, H. Xargay, An experimental study on the post-cracking behaviour of 598 Hybrid Industrial/Recycled Steel Fibre-Reinforced Concrete, Construction and Building Materials, 94 $599 \quad$ (2015) 290-298.

600 [33] M.S. Meddah, M. Bencheikh, Properties of concrete reinforced with different kinds of industrial 601 waste fibre materials, Construction and Building Materials 23(10) (2009) 3196-3205.

602 [34] D. Yoo, H. Shin, J. Yang, Y. Yoon, Material and bond properties of ultra high performance fiber 603 reinforced concrete with micro steel fibers, Composites Part B: Engineering 58 (2014) 122-133.

604 [35] A.S. Ezeldin, P.N. Balaguru, Normal-and high-strength fiber-reinforced concrete under 605 compression, Journal of materials in civil engineering 4(4) (1992) 415-429.

606 [36] D. Yoo, J. Lee, Y. Yoon, Effect of fiber content on mechanical and fracture properties of ultra high 607 performance fiber reinforced cementitious composites, Composite Structures 106 (2013) 742-753.

608 [37] F. Altun, T. Haktanir, K. Ari, Effects of steel fiber addition on mechanical properties of concrete 609 and RC beams, Construction and Building Materials 21(3) (2007) 654-661.

610 [38] W. Zheng, B. Luo, Y. Wang, Microstructure and mechanical properties of RPC containing PP fibres 611 at elevated temperatures, Magazine of Concrete Research 66(8) (2014) 397-408.

612 [39] Australian Standards, Methods of testing concrete - Method for making and curing concrete 613 Compression and indirect tensile test specimens, AS 1012.8.1, AS, Sydney, NSW, Australia., 2014.

614 [40] ASTM, 230/C230M, Standard specification for flow table for use in tests of hydraulic cement, 615 ASTM International, West Conshohocken (2008).

616 [41] R. Yu, P. Spiesz, H. Brouwers, Mix design and properties assessment of ultra-high performance 617 fibre reinforced concrete (UHPFRC), Cement and concrete research 56 (2014) 29-39.

618 [42] Z. Wu, C. Shi, W. He, L. Wu, Effects of steel fiber content and shape on mechanical properties of 619 ultra high performance concrete, Construction and Building Materials 103 (2016) 8-14.

620 [43] Chinese National Standard, Test Methods for Flowability of Cement Paste, GB2419-2005, Beijing, 621 China (2005).

622 [44] Australian Standards, Methods of testing concrete - Compressive strength tests - Concrete, 623 mortar and grout specimens, AS 1012.9, AS, 2014. 
624 [45] ACI Report, State-of-the-Art Report on Fiber Reinforced Concrete, in: 544.1R-96 (Ed.) American 625 Concrete Institute, Detroit, 1996.

626 [46] S. Haroon, N. Yazdani, K. Tawfiq, Posttensioned anchorage zone enhancement with fiber627 reinforced concrete, Journal of Bridge Engineering 11(5) (2006) 566-572.

628 [47] C.D. Atiş, O. Karahan, Properties of steel fiber reinforced fly ash concrete, Construction and 629 Building Materials 23(1) (2009) 392-399.

630 [48] M.A. Yusof, N.M. Nor, M.F.M. Zain, N.C. Peng, A. Ismail, R.M. Sohaimi, A.M.A. Zaidi, Mechanical 631 properties of hybrid steel fibre reinforced concrete with different aspect ratio, Australian Journal of 632 Basic and Applied Sciences 5(7) (2011) 159-166.

633 [49] Australian Standards, Methods of testing concrete - Determination of indirect tensile strength of 634 concrete cylinders (Brasil or splitting test), AS 1012.10, AS, 2014.

635 [50] R.V. Balendran, F.P. Zhou, A. Nadeem, A.Y.T. Leung, Influence of steel fibres on strength and 636 ductility of normal and lightweight high strength concrete, Building and Environment 37(12) (2002) 637 1361-1367.

638 [51] W. Yao, J. Li, K. Wu, Mechanical properties of hybrid fiber-reinforced concrete at low fiber volume 639 fraction, Cement and Concrete Research 33(1) (2003) 27-30.

640 [52] Australian Standards, AS 1012.17: Methods of testing concrete - Determination of the static chord 641 modulus of elasticity and Poisson's ratio of concrete specimens, Standards Australia, Sydney (2014).

642 [53] Australian Standards, AS 1545.17: Methods for the calibration and grading of extensometers, 643 Standards Australia, Sydney (2017).

644 [54] L.R. Taerwe, Influence of steel fibers on strain-softening of high-strength concrete, ACl Materials 645 Journal 89(1) (1992) 54-60.

646 [55] V.S. Gopalaratnam, S.P. Shah, Tensile failure of steel fiber-reinforced mortar, Journal of 647 Engineering Mechanics 113(5) (1987) 635-652.

648 [56] $\mathrm{ACl}$ Committee, Building code requirements for reinforced concrete, $\mathrm{ACl}$ 318-11, American 649 Concrete Institute, (2011).

650 [57] E.P.Y. PAWADE, D.A. PANDE, D.P. NAGARNAIK, Effect of steel fibers on modulus of elasticity of 651 concrete, IJAEST-INTERNATIONAL JOURNAL OF ADVANCED ENGINEERING SCIENCES AND 652 TECHNOLOGIES 1(7) (2011) 169-177.

653 [58] S. Ahmad, I. Hakeem, A.K. Azad, Effect of curing, fibre content and exposures on compressive 654 strength and elasticity of UHPC, Advances in Cement Research 27(4) (2015) 233-239.

655 [59] M. Gul, A. Bashir, J.A. Naqash, Study of modulus of elasticity of steel fiber reinforced concrete, 656 International Journal of Engineering and Advanced Technology 3(4) (2014) 304-309. 
659 Table 1: The chemical composition of cement.

660 Table 2: The chemical composition of silica fume.

661 Table 3: The experimental test matrix.

662 Table 4: The average experimental results of the compressive strength, tensile strength and 663 modulus of elasticity of the tested RPC specimens.

664 Table 5: The typical experimental results of the peak stress, corresponding strain, toughness 665 and Toughness Index of the tested RPC specimens.

666

667

668

669

670

671

672

673

674

675

676

677

678

679

680

681

682 
684 Fig. 1: WF measurements, (a): The WF range of lengths (mm) vs frequency (\%), (b): The WF

685

686

687

688

689

690

691

692

693

694

695

696

697

698

699

700

701

702

703

704

705

706

707

range of diameters $(\mathrm{mm})$ vs frequency $(\%)$.

Fig. 2: Types of steel fibres utilized in this study: (a) industrial micro steel fibre (MF), (b) industrial deformed steel fibre (DF), (c) waste steel fibre (WF) recovered from waste tyres, (d) range of lengths of the waste steel fibre (WF).

Fig. 3: The vertical mixing machine.

Fig. 4: Capping of WF2 specimens.

Fig. 5: Flowability testing apparatus.

Fig. 6: Flowability of RPC.

Fig. 7: Compressive strength test: (a) compressive strength testing machine, (b) Specimen MF1 under compression.

Fig. 8: Average compressive strength of RPC specimens.

Fig. 9: Typical failure mode of RPC specimens tested under compression.

Fig. 10: Specimen DF1 tested under indirect tension.

Fig. 11: Average tensile strength of the RPC specimens.

Fig. 12: Specimen WF3 under compression.

Fig. 13: Typical compressive stress-strain relationships: (a) Specimens NF, MF1, DF1, WF1, (b) Specimens NF, MF2, DF2, WF2, (c) Specimens NF, MF3, DF3, WF3, (d) Specimens NF, MF4, DF4, WF4, (e) Specimens NF, HF and WHF.

Fig. 14: The average Toughness Index vs the average compressive strength of RPC specimens.

Fig. 15: The average modulus of elasticity vs the average compressive strength of RPC specimens.

Fig. 16: The rate of increase in the compressive strength to modulus of elasticity of the tested specimens. 
714

715

Table 1: The chemical composition of cement [27]

\begin{tabular}{lc}
\hline Composition (mass) & Content (\%) \\
\hline Portland Cement Clinker & $<97$ \\
Gypsum $\left(\mathrm{CaSO}_{4} 2 \mathrm{H}_{2} \mathrm{O}\right)$ & $2-5$ \\
Limestone $\left(\mathrm{CaCO}_{3}\right)$ & $0-7.5$ \\
Calcium Oxide & $0-3$ \\
Hexavalent Chromium $\mathrm{Cr}(\mathrm{VI})$ & $<20 \mathrm{ppm}$ \\
Crystalline Silica (Quartz) & $<1$ \\
\hline
\end{tabular}

716

717

718

719

720

721

722

723

724

725

726

Page 28 of 50 
Table 2: The chemical composition of silica fume [28]

\begin{tabular}{lc}
\hline Composition (mass) & Content $(\%)$ \\
\hline Silicon as $\mathrm{SiO}_{2}$ & 93.16 \\
Moisture Content & 0.23 \\
Loss on Ignition & 3.00 \\
$\mathrm{Fe}_{2} \mathrm{O}_{3}$ & 0.11 \\
$\mathrm{Al}_{2} \mathrm{O}_{3}$ & 0.82 \\
$\mathrm{CaO}$ & 0.30 \\
$\mathrm{MgO}$ & 0.62 \\
$\mathrm{~K}_{2} \mathrm{O}$ & 0.51 \\
$\mathrm{Na}$ & 0.43 \\
$\mathrm{C}$ & 0.01 \\
$\mathrm{SO}$ & 0.00 \\
$\mathrm{Free}_{3}$ & 0.01 \\
$\mathrm{Cl}$ & 0.00 \\
\hline
\end{tabular}


Table 3: The experimental test matrix.

\begin{tabular}{|c|c|c|}
\hline Group & Type of steel fibre & Percentage \\
\hline $\mathrm{NF}$ & - & - \\
\hline MF1 & Micro steel fibre & $1 \%$ \\
\hline MF2 & & $2 \%$ \\
\hline MF3 & & $3 \%$ \\
\hline MF4 & & $4 \%$ \\
\hline DF1 & Deformed steel fibre & $1 \%$ \\
\hline DF2 & & $2 \%$ \\
\hline DF3 & & $3 \%$ \\
\hline DF4 & & $4 \%$ \\
\hline WF1 & Waste steel fibre & $1 \%$ \\
\hline WF2 & & $2 \%$ \\
\hline WF3 & & $3 \%$ \\
\hline WF4 & & $4 \%$ \\
\hline $\mathrm{HF}$ & Industrial hybrid steel fibre & $3 \%$ \\
\hline WHF & Waste-industrial hybrid steel fibre & $3 \%$ \\
\hline
\end{tabular}


750

751

752 Table 4: The average experimental results of the compressive strength, tensile strength and 753 modulus of elasticity of the tested RPC specimens.

\begin{tabular}{|c|c|c|c|}
\hline Group & $\begin{array}{c}\text { Compressive } \\
\text { strength } \\
(\mathrm{MPa}) \\
\end{array}$ & $\begin{array}{l}\text { Tensile } \\
\text { strength } \\
(\mathrm{MPa})\end{array}$ & $\begin{array}{l}\text { Modulus of elasticity }(E) \\
(\mathrm{GPa})\end{array}$ \\
\hline $\mathrm{NF}$ & 100.2 & 10.3 & 37.2 \\
\hline MF1 & 111.8 & 15.3 & 39.8 \\
\hline MF2 & 120.4 & 18.3 & 40.3 \\
\hline MF3 & 121.3 & 21.9 & 42.1 \\
\hline MF4 & 134.0 & 24.9 & 44.1 \\
\hline DF1 & 100.4 & 11.8 & 37.7 \\
\hline DF2 & 102.2 & 14.2 & 39.7 \\
\hline DF3 & 100.4 & 11.4 & 38.9 \\
\hline DF4 & 100.1 & 10.6 & 38.6 \\
\hline WF1 & 109.9 & 15.3 & 38.4 \\
\hline WF2 & 115.6 & 17.4 & 40.6 \\
\hline WF3 & 121.0 & 23.2 & 42.0 \\
\hline WF4 & 110.6 & 16.3 & 40.4 \\
\hline $\mathrm{HF}$ & 125.1 & 19.7 & 41.8 \\
\hline WHF & 124.5 & 19.4 & 42.4 \\
\hline
\end{tabular}


761 Table 5: The typical experimental results of the peak stress, corresponding strain, toughness

762 and Toughness Index of the tested RPC specimens.

\begin{tabular}{|c|c|c|c|c|}
\hline Group & $\begin{array}{c}\text { Peak stress } \\
(\mathrm{MPa})\end{array}$ & $\begin{array}{c}\text { Strain at peak stress } \\
(\mathrm{mm} / \mathrm{mm})\end{array}$ & $\begin{array}{c}\text { Toughness } \\
\left(\mathrm{MPa} * 10^{-3}\right) \\
\end{array}$ & $\begin{array}{c}\text { Toughness Index } \\
(T I)\end{array}$ \\
\hline $\mathrm{NF}$ & 96.9 & 0.00273 & 133 & 1.0 \\
\hline MF1 & 105.8 & 0.00288 & 172 & 1.3 \\
\hline MF2 & 116.1 & 0.00312 & 287 & 2.2 \\
\hline MF3 & 119.7 & 0.00327 & 336 & 2.5 \\
\hline MF4 & 128.1 & 0.00353 & 464 & 3.5 \\
\hline DF1 & 97.4 & 0.00273 & 219 & 1.7 \\
\hline DF2 & 98.3 & 0.00279 & 262 & 2.0 \\
\hline DF3 & 97.6 & 0.00275 & 149 & 1.1 \\
\hline DF4 & 97.2 & 0.00274 & 148 & 1.1 \\
\hline WF1 & 109.4 & 0.00309 & 291 & 2.2 \\
\hline WF2 & 111.1 & 0.00312 & 286 & 2.2 \\
\hline WF3 & 117.1 & 0.00335 & 343 & 2.6 \\
\hline WF4 & 109.7 & 0.00302 & 289 & 2.2 \\
\hline $\mathrm{HF}$ & 124.2 & 0.00364 & 458 & 3.5 \\
\hline WHF & 123.9 & 0.00344 & 412 & 3.1 \\
\hline
\end{tabular}

763 


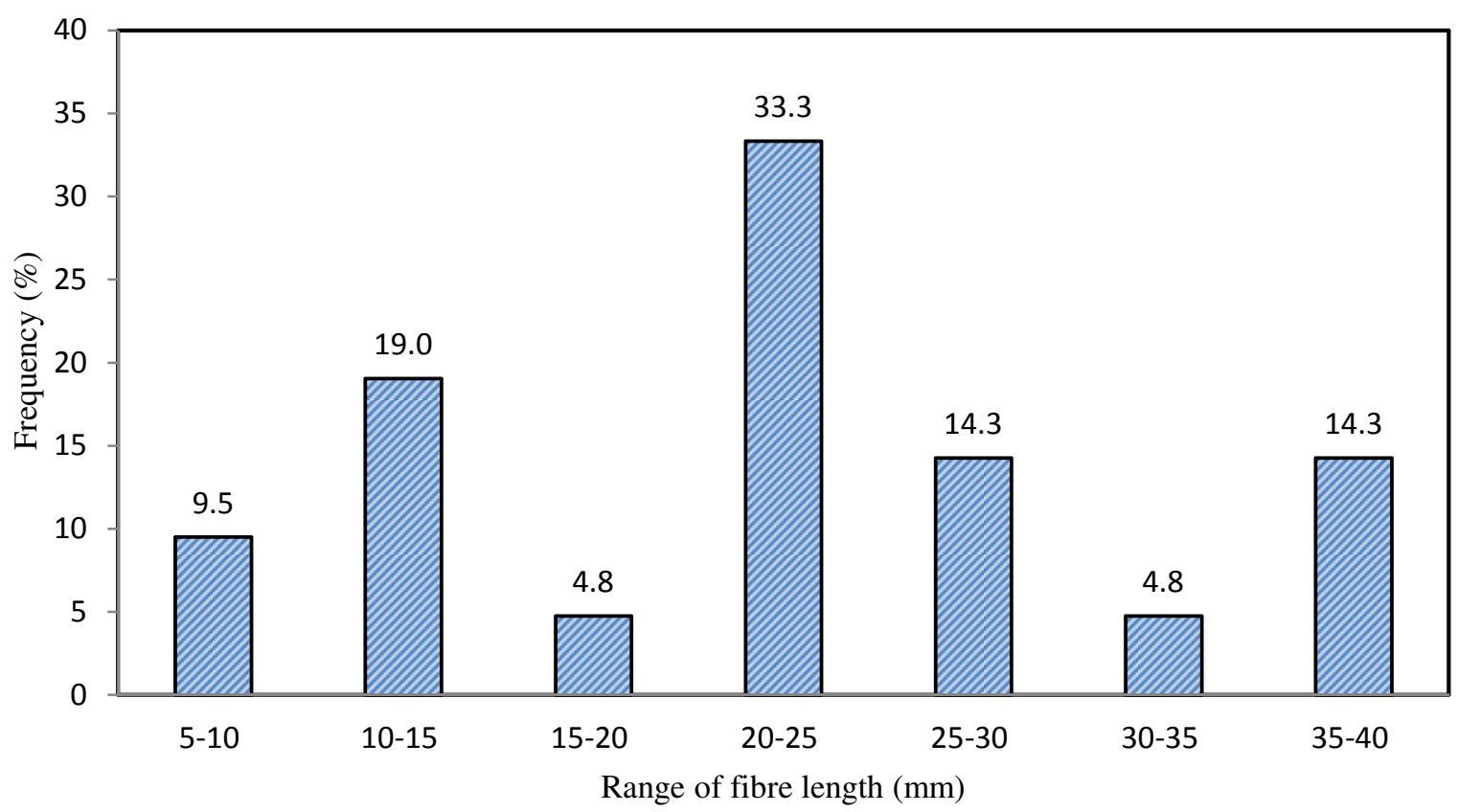

768

769

(a)

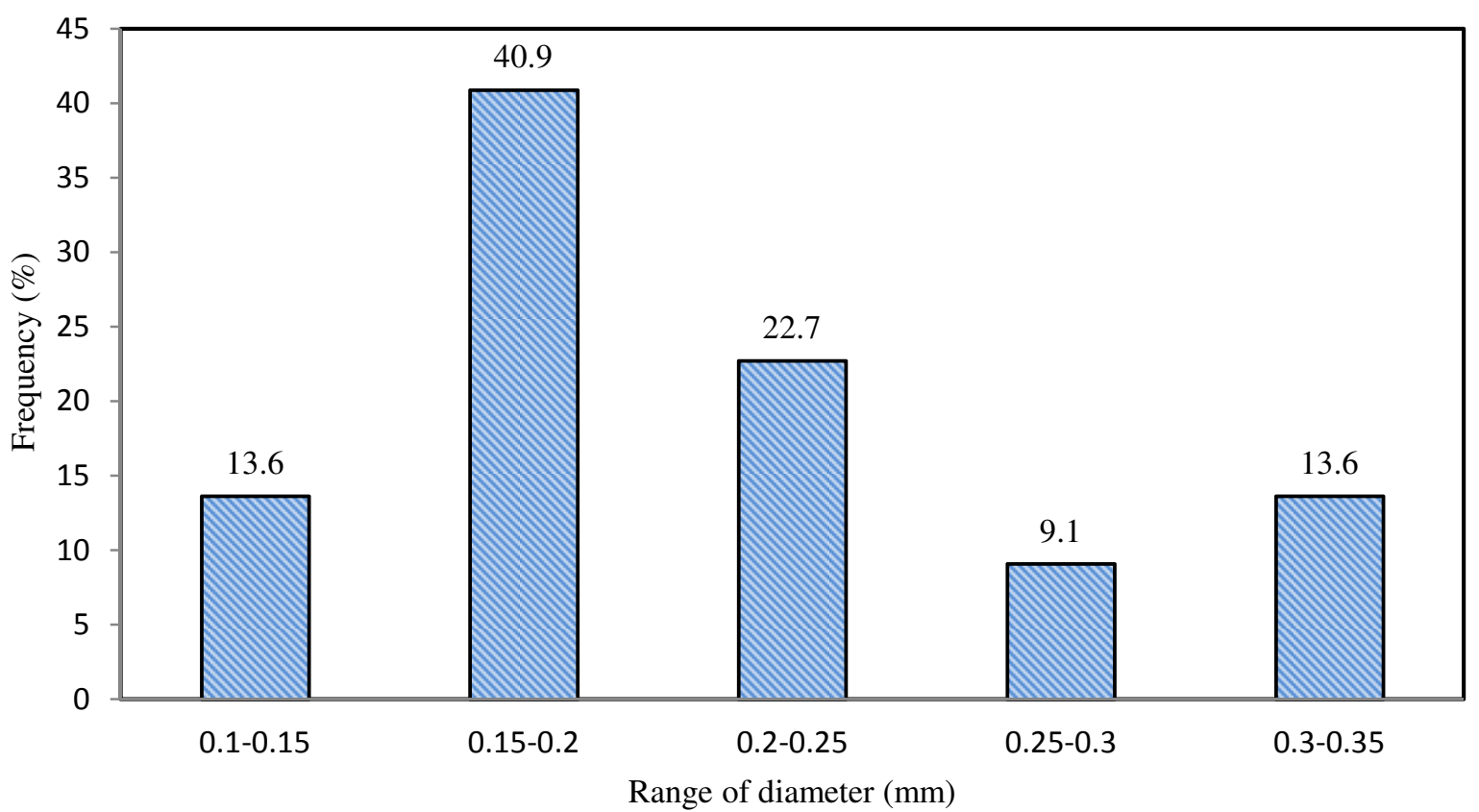

770

(b)

772 Fig. 1: WF measurements, (a): The WF range of lengths (mm) vs frequency (\%), (b): The WF range of diameters $(\mathrm{mm})$ vs frequency $(\%)$. 

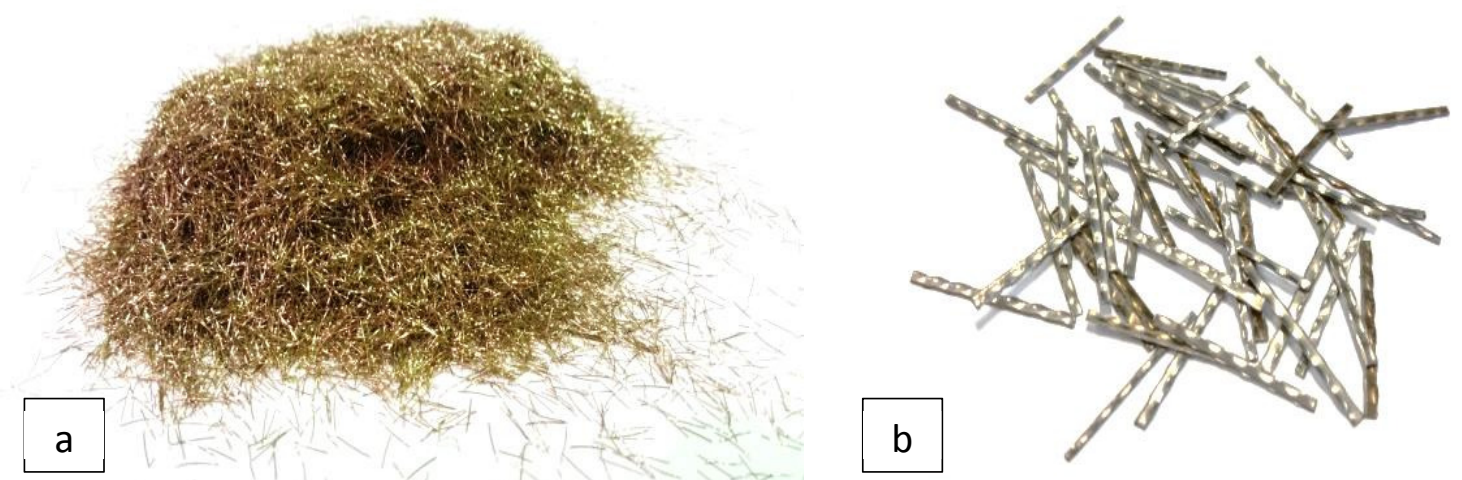

779
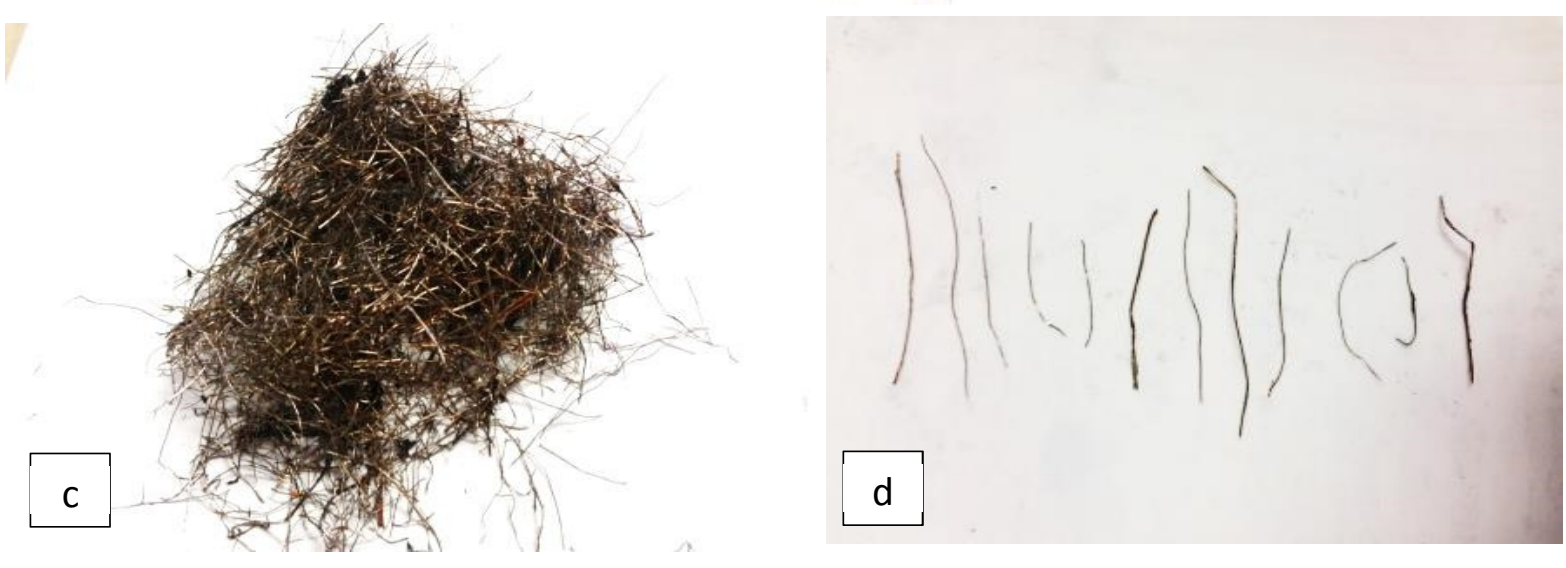

780

Fig. 2: Types of steel fibres utilized in this study: (a) industrial micro steel fibre (MF), (b)

782 industrial deformed steel fibre (DF), (c) waste steel fibre (WF) recovered from waste tyres, (d) range of lengths of the waste steel fibre (WF). 


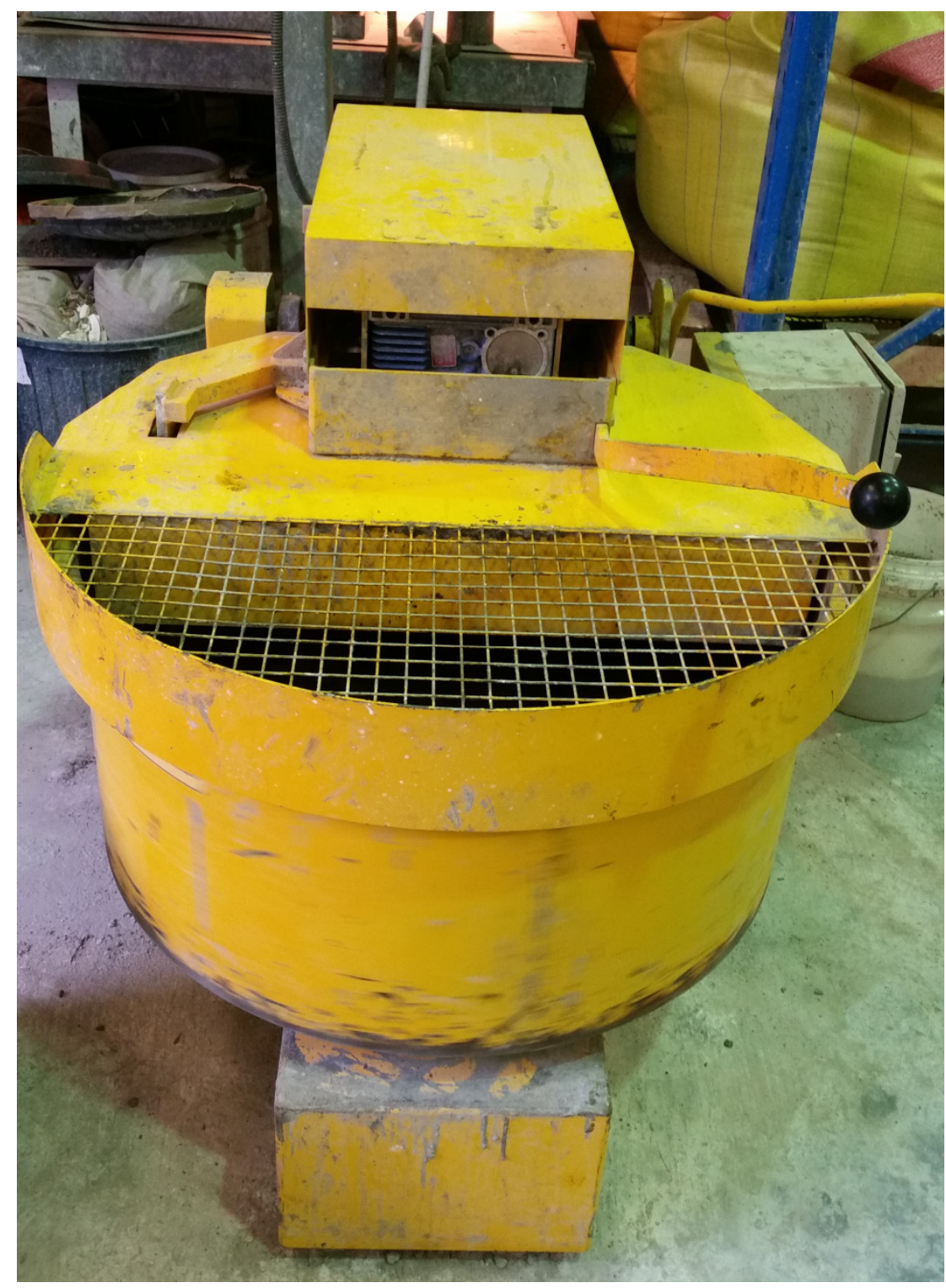

Fig. 3: The vertical mixing machine.

795

796 
799

800

801

802

803

804

805

806

807

Fig. 4: Capping of WF2 specimens.

808

809

810

811

812

813

814

815

Page 36 of 50 


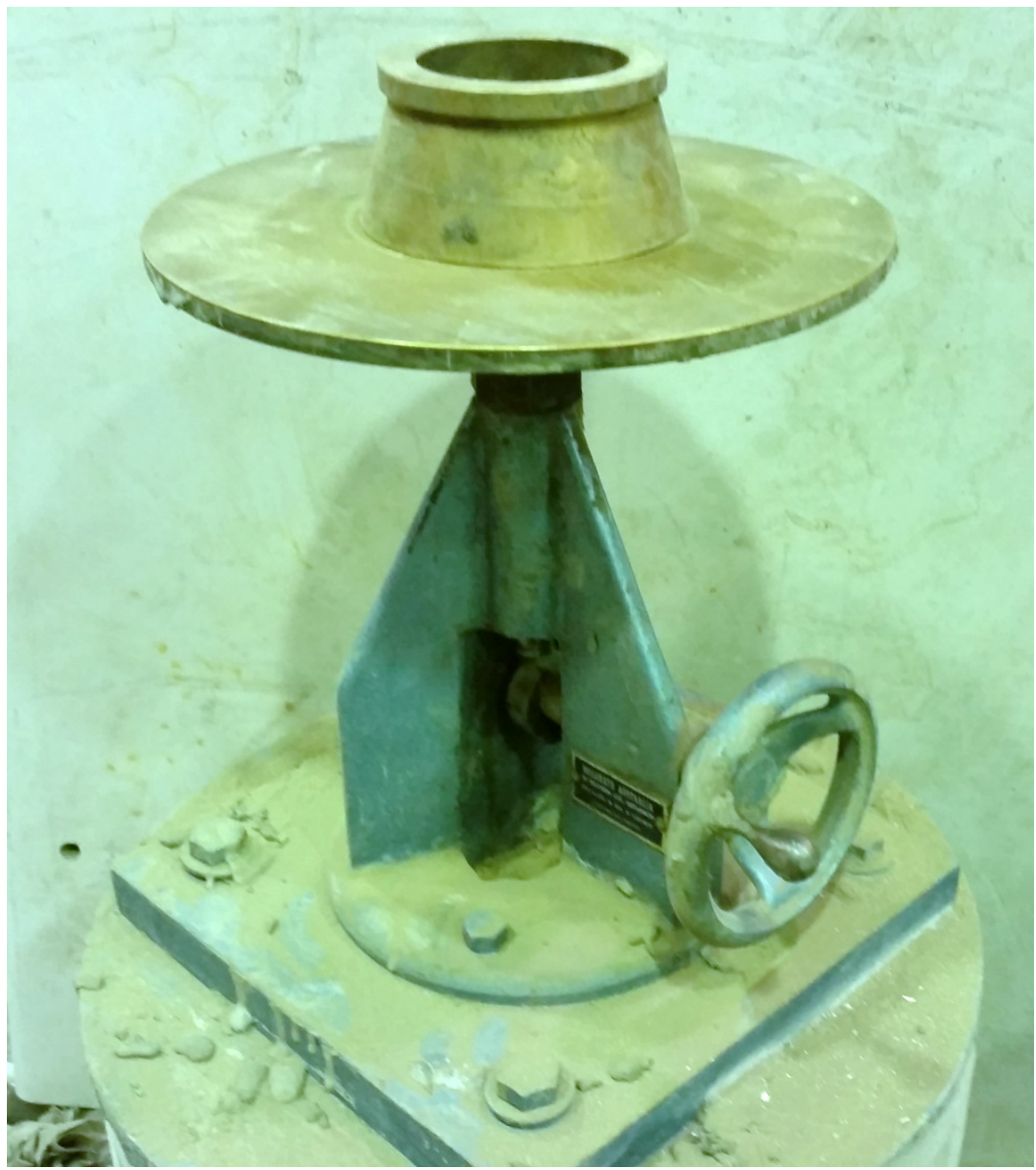

Fig. 5: Flowability testing apparatus.

825

826

827 


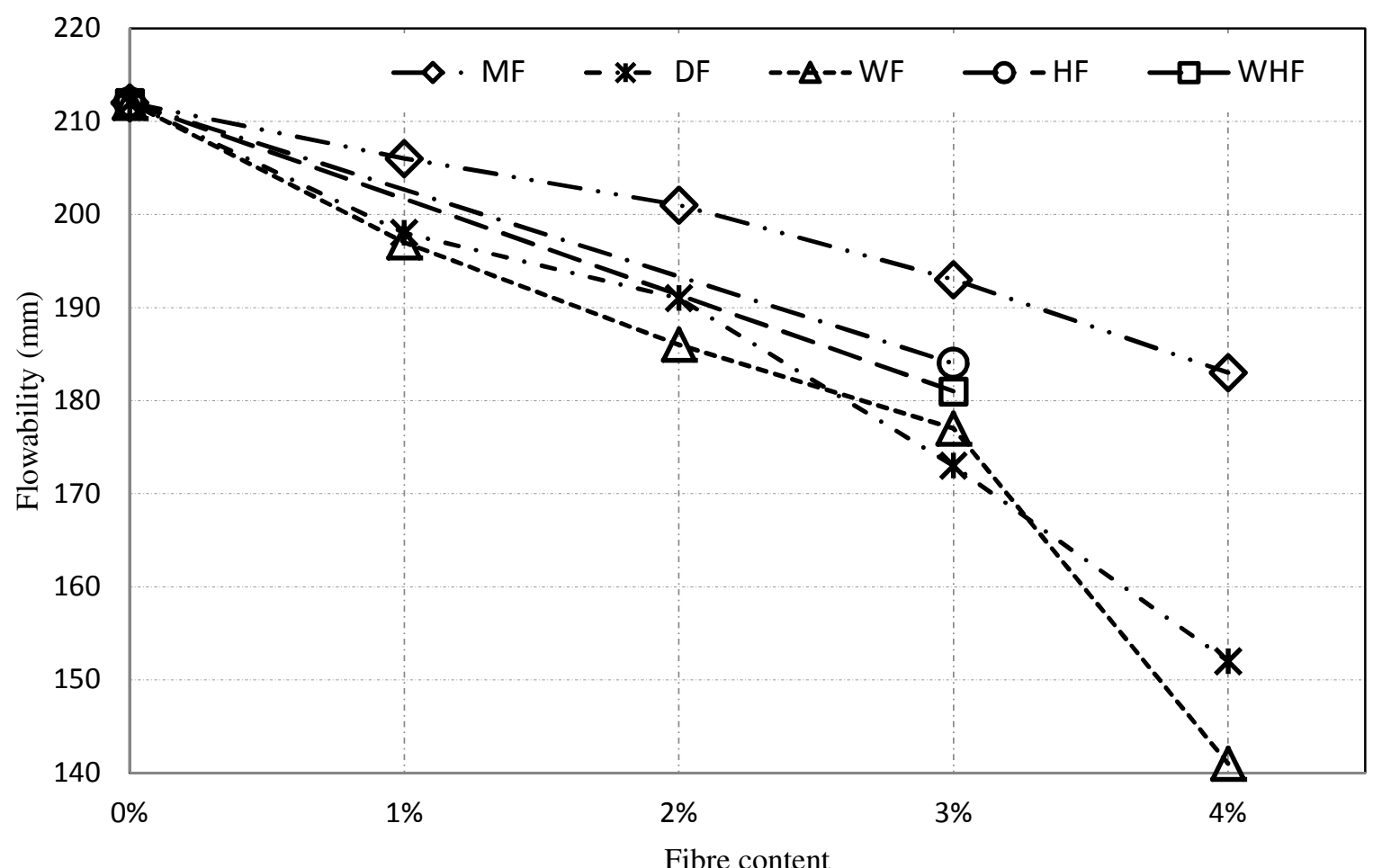

835

Fig. 6: Flowability of RPC. 


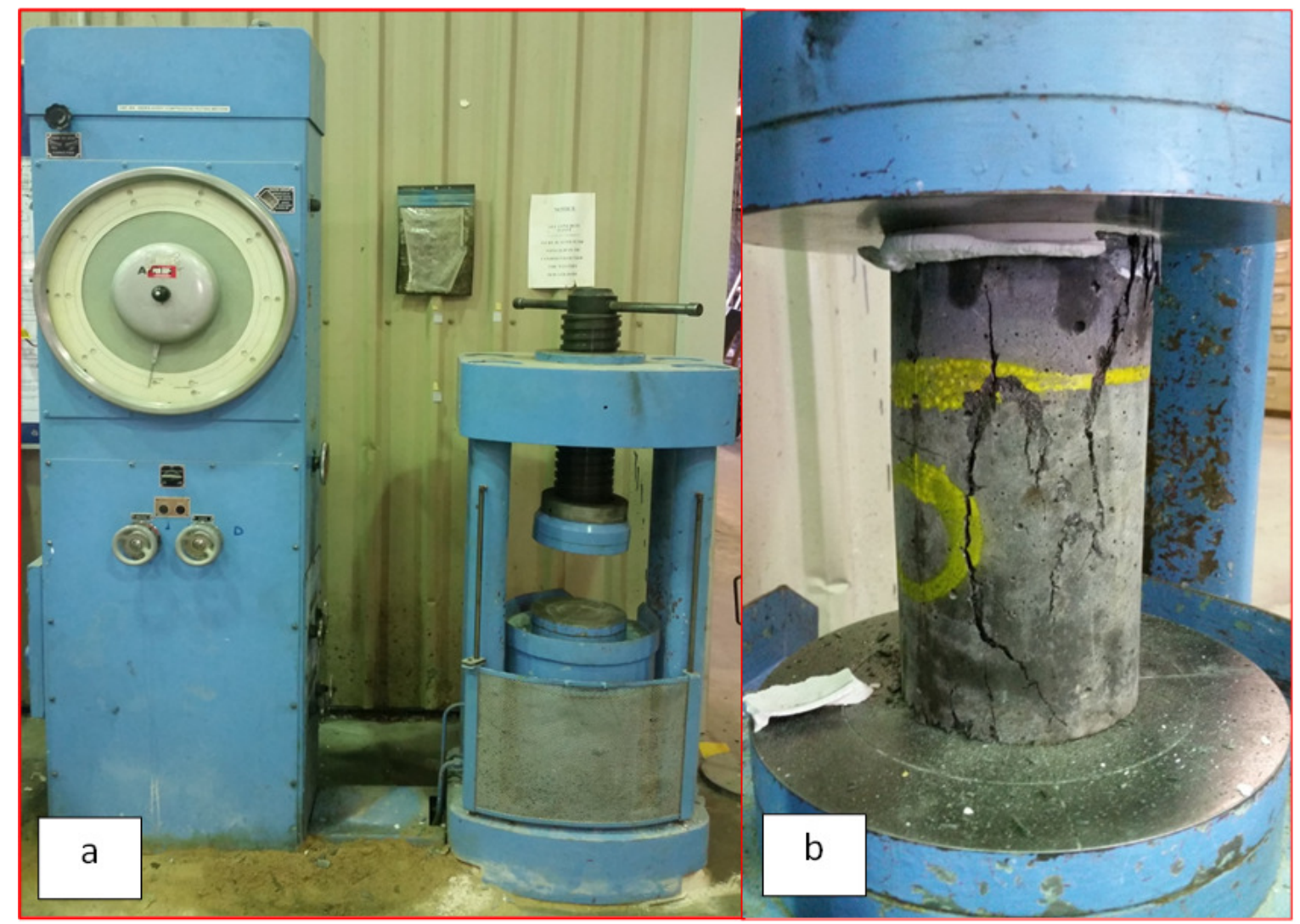

Fig. 7: Compressive strength test: (a) The compressive strength testing machine, (b) Specimen MF1 under compression. 


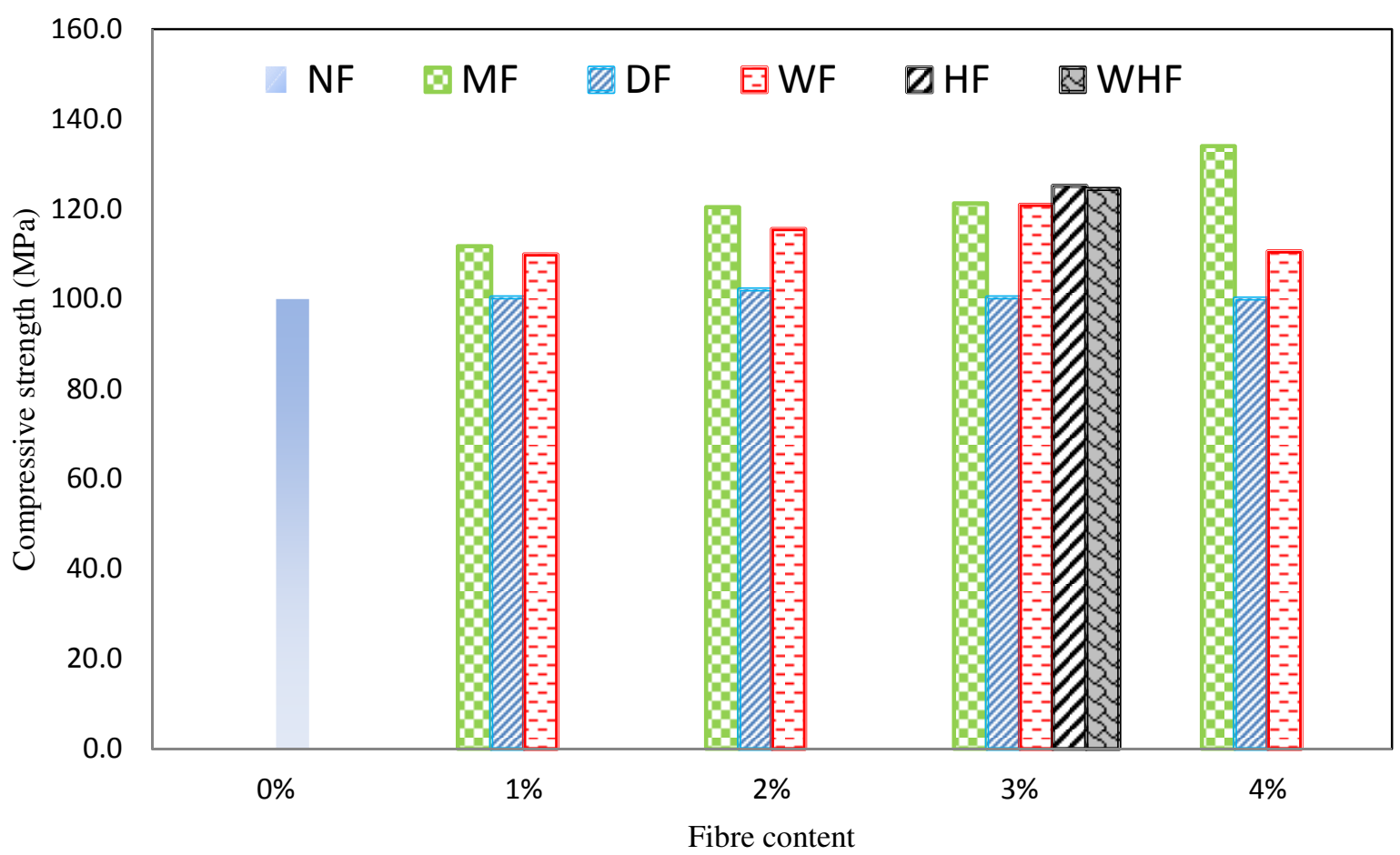

863

Fig. 8: Average compressive strength of RPC specimens.

865

866

867

868

869

870

871

872

873

874

Page 40 of 50 

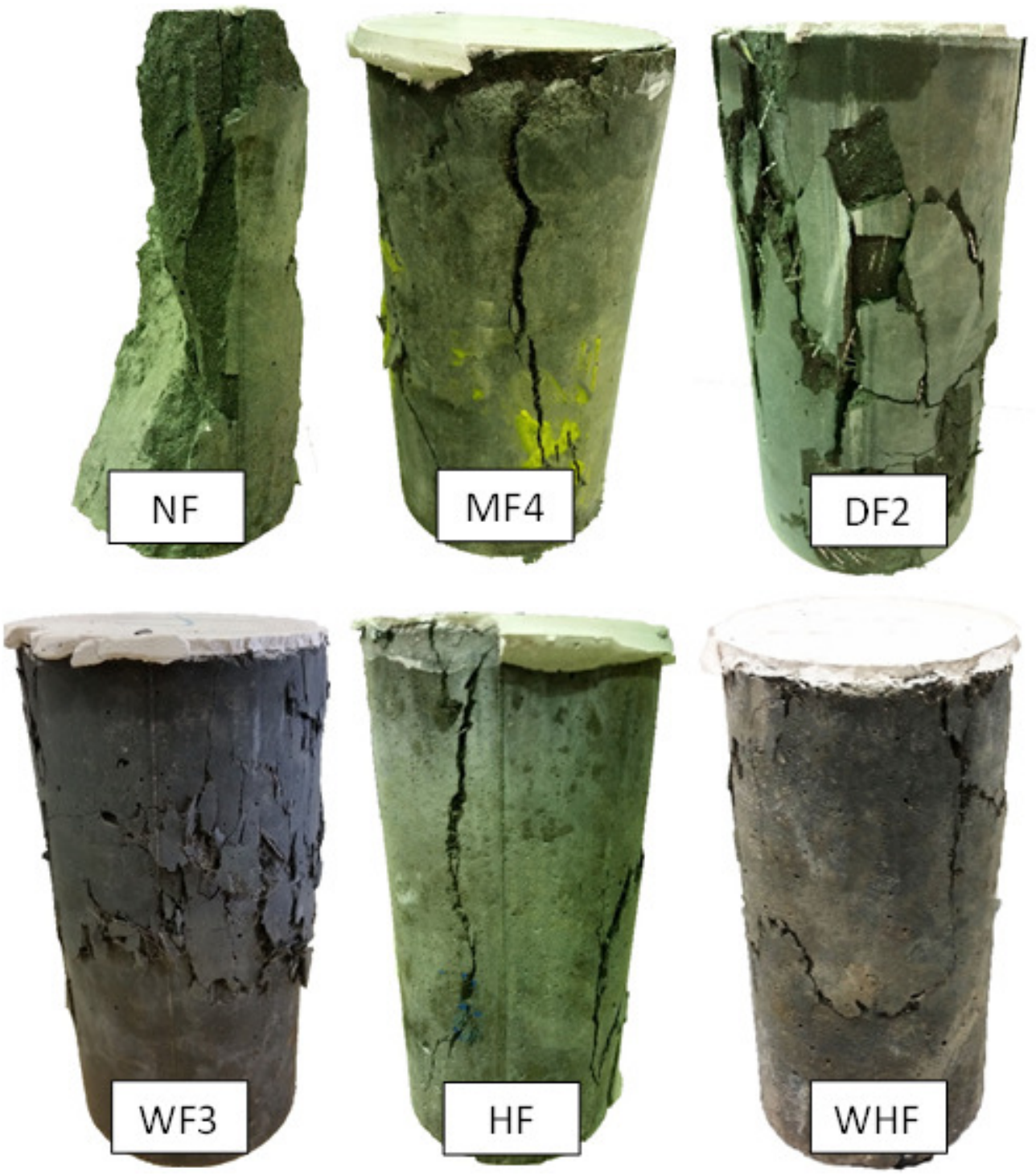

880

Fig. 9: Typical failure mode of RPC specimens tested under compression. 


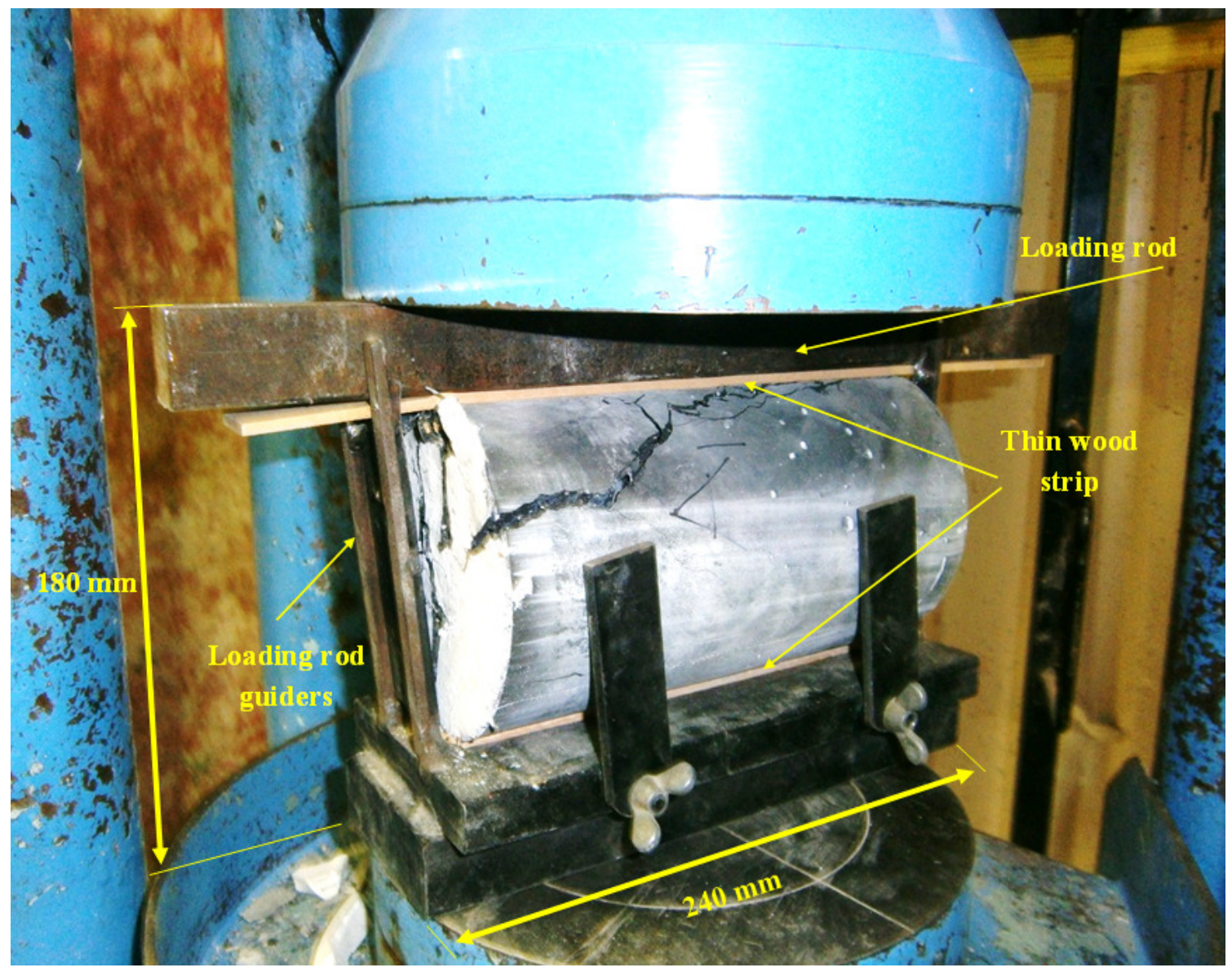


900

901

902

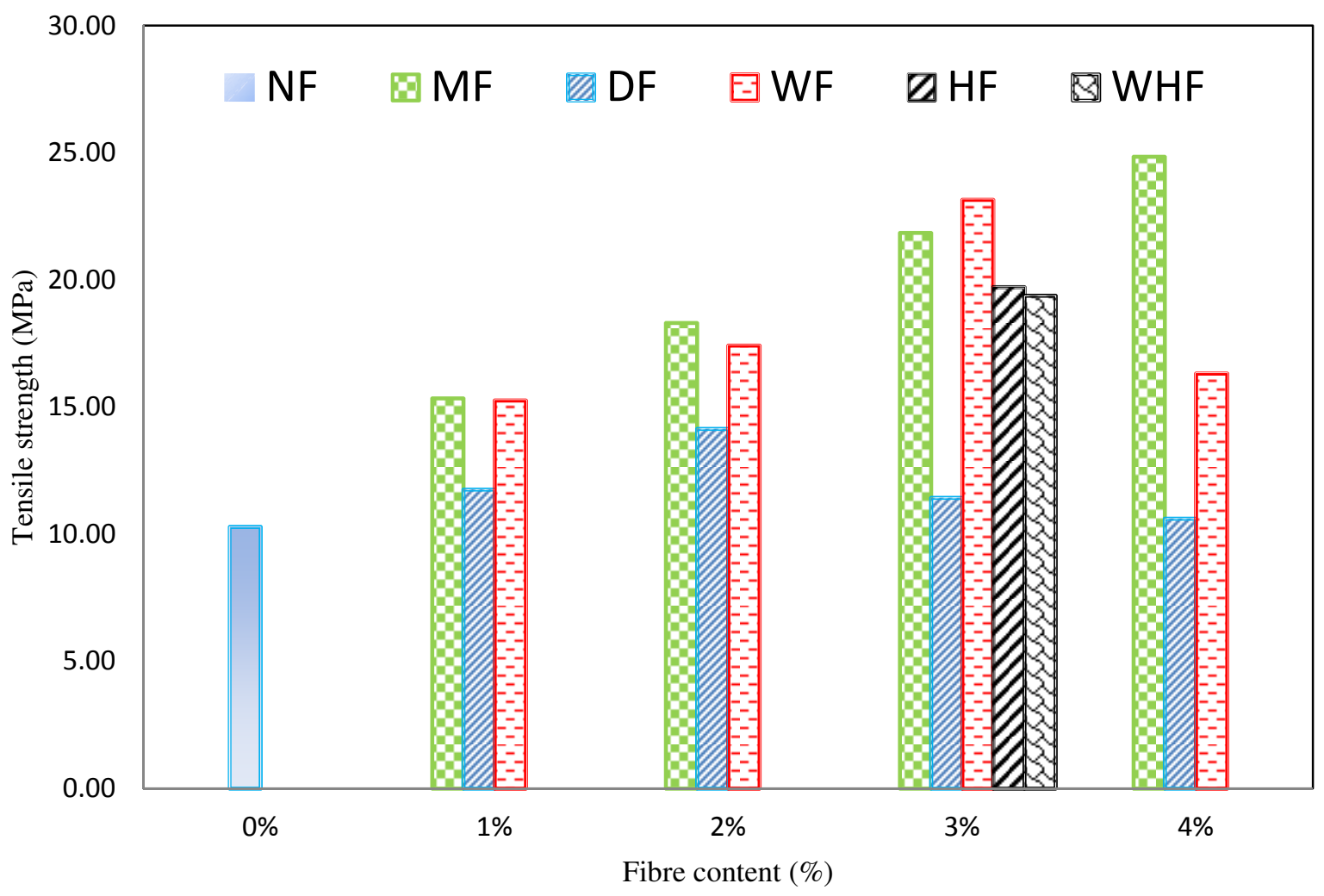

903

Fig. 11: Average tensile strength of the RPC specimens.

905

906

907

908

909

910

911

912

913

Page 43 of 50 


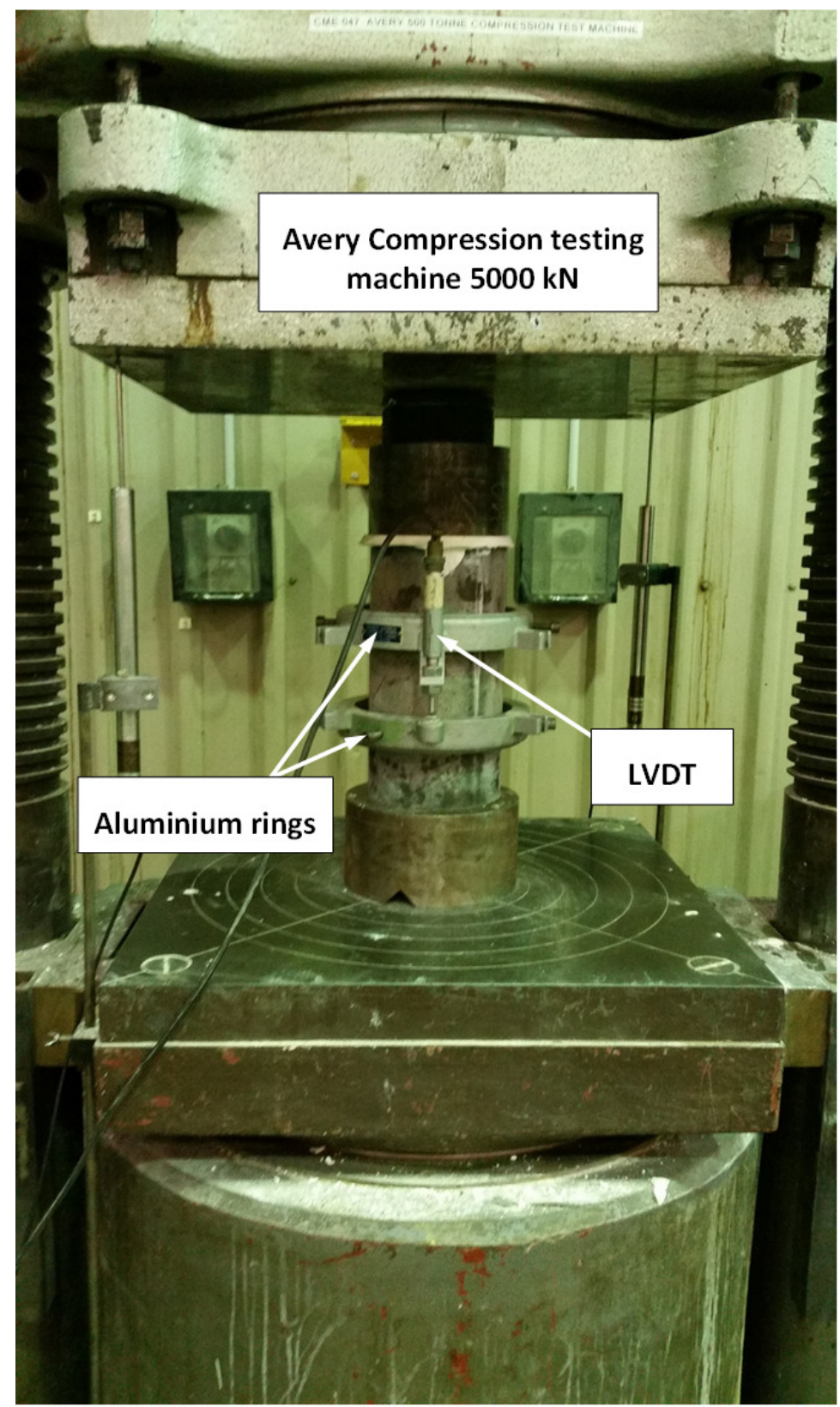

Fig. 12: Specimen WF3 under compression. 


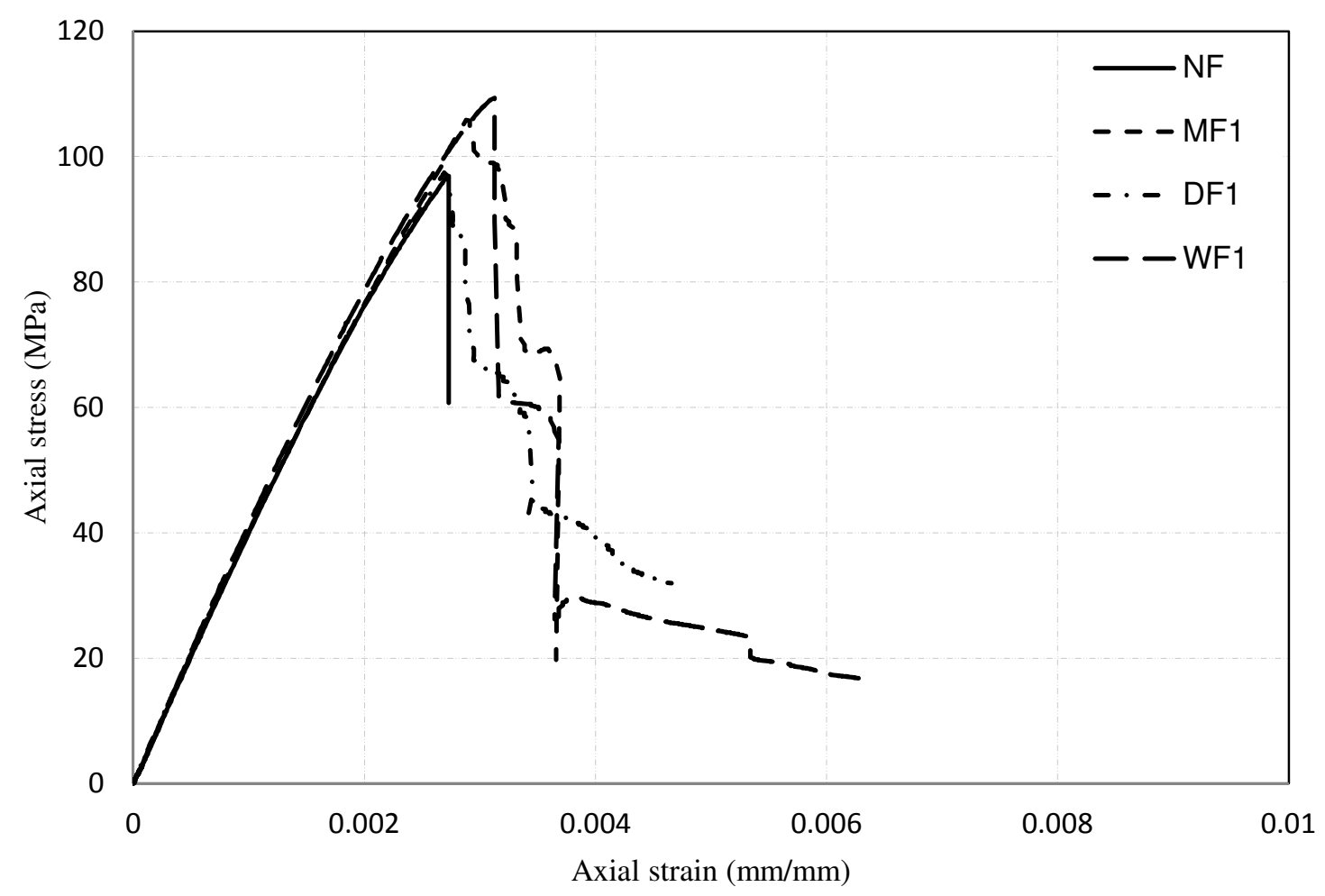

925

(a)

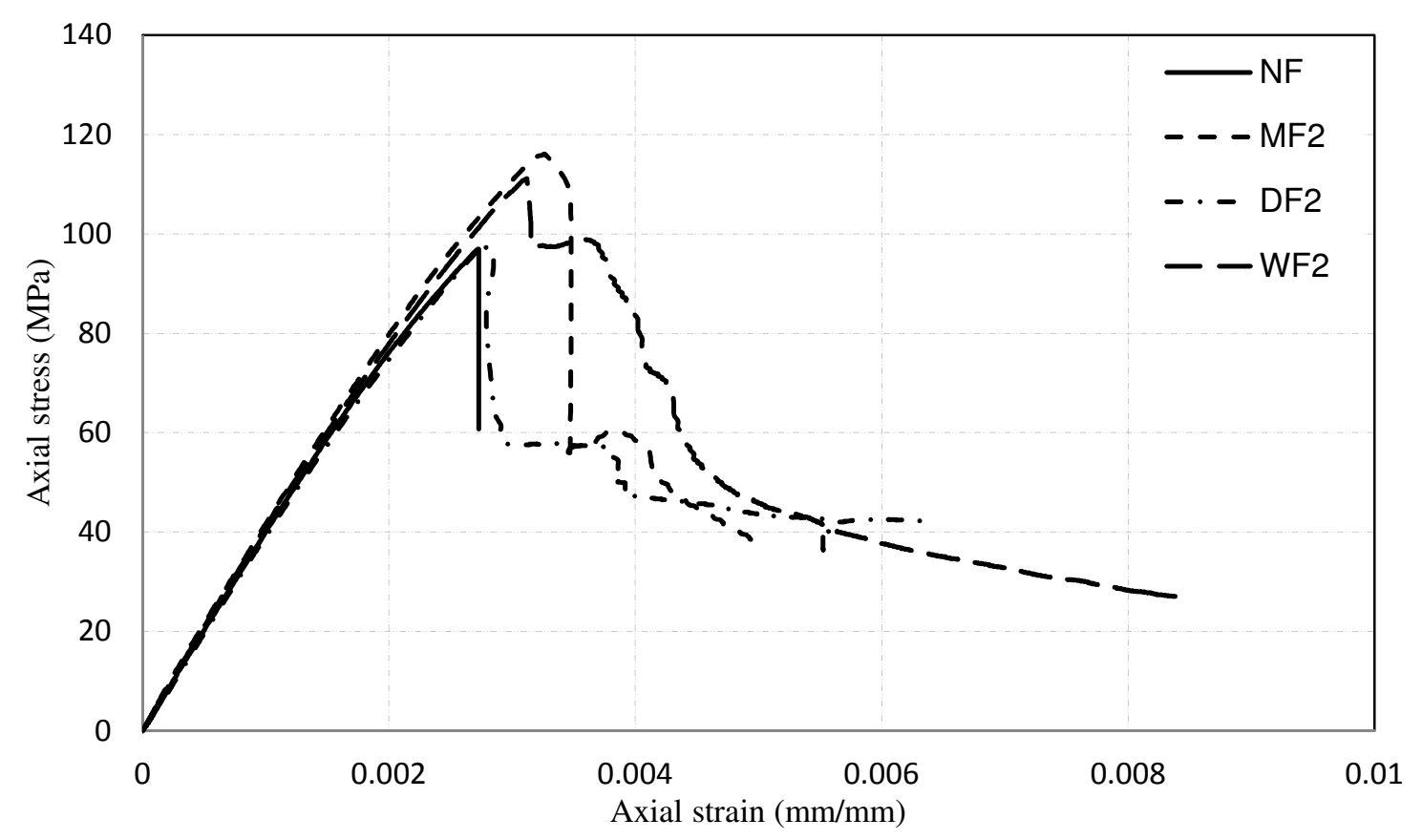

(b) 


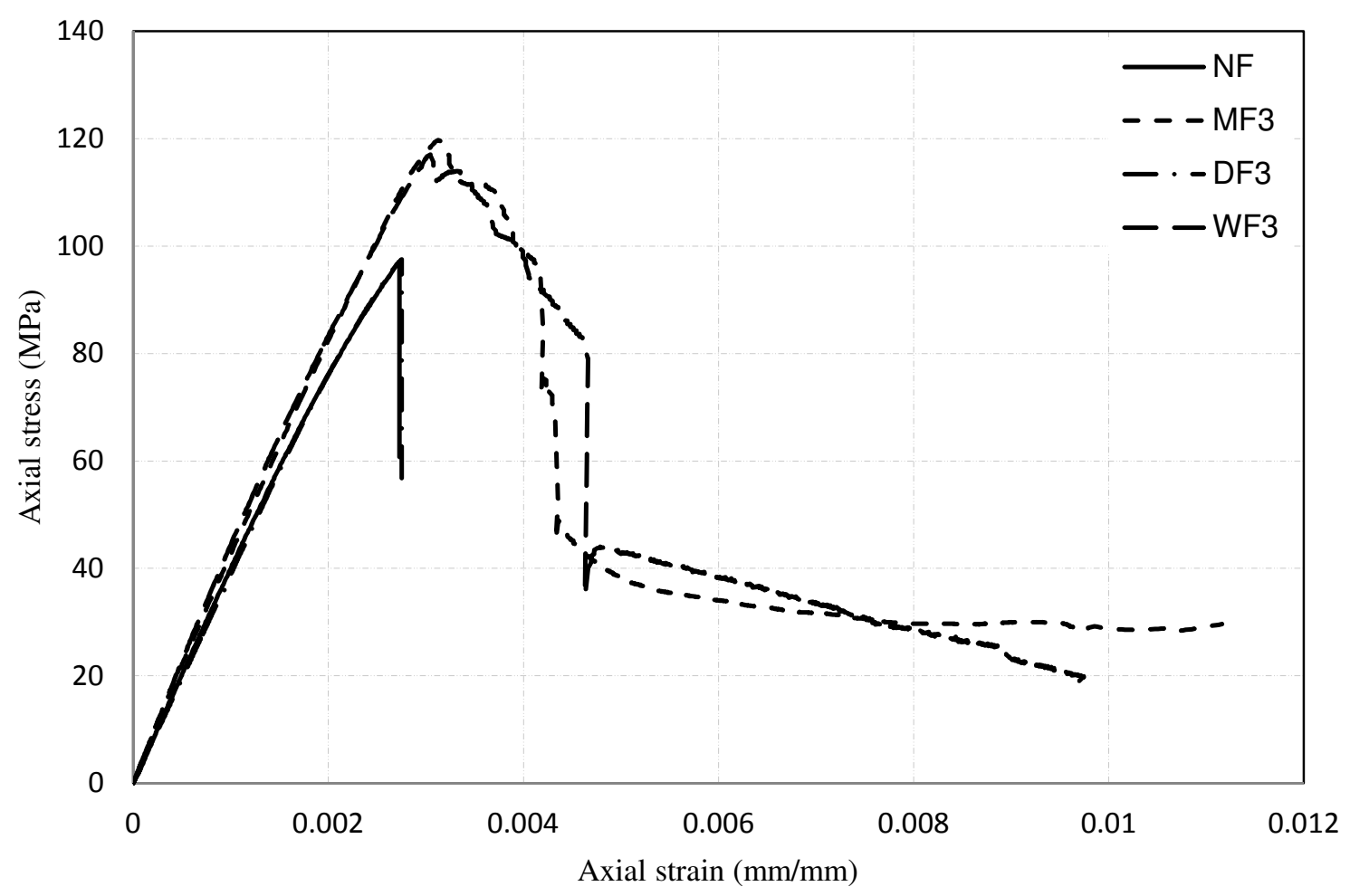

931

932 (c)

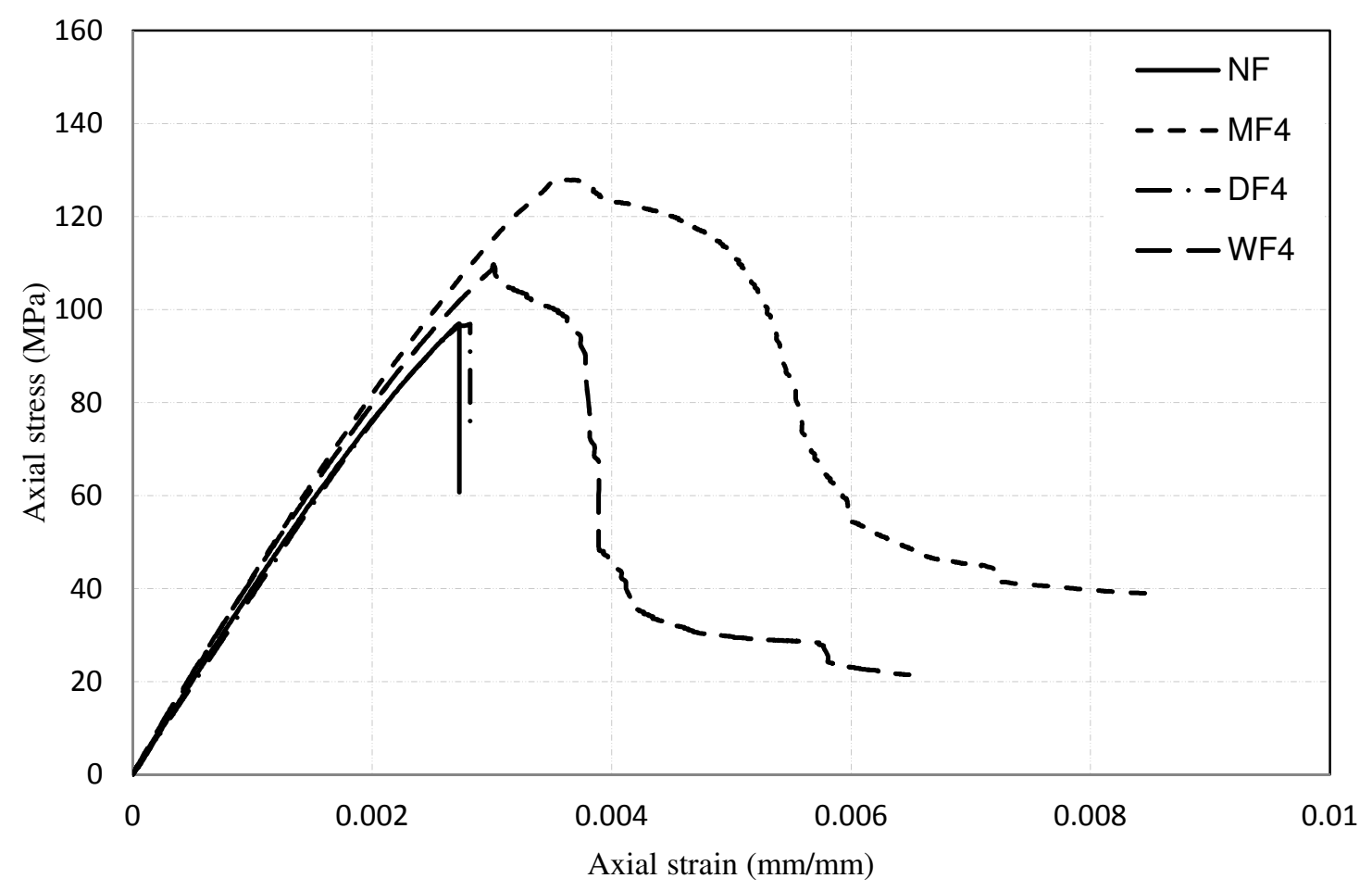

933

(d) 


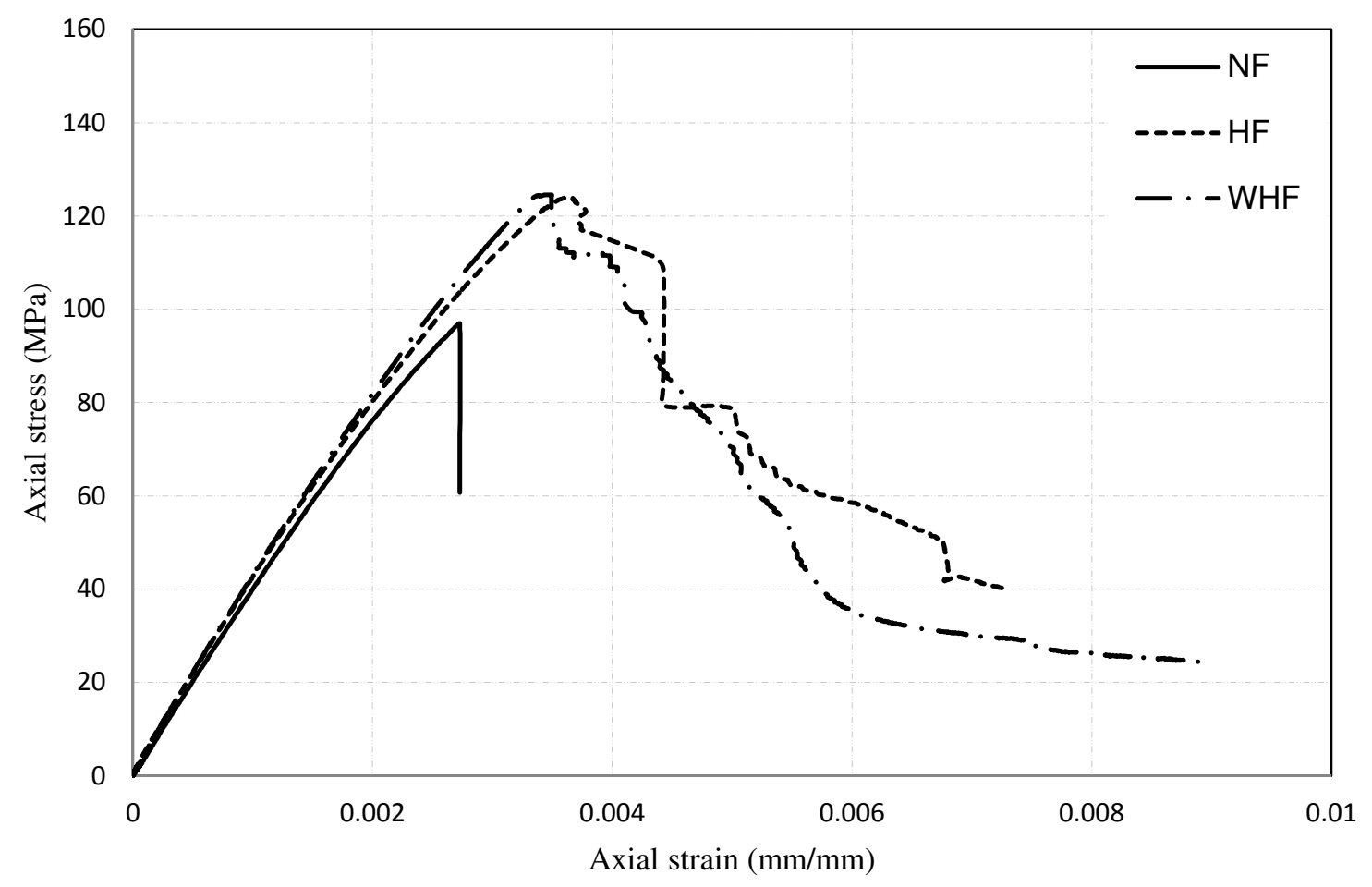

939

940

(e)

941

Fig. 13: Typical compressive stress-strain relationships: (a) Specimens NF, MF1, DF1, WF1,

942

(b) Specimens NF, MF2, DF2, WF2, (c) Specimens NF, MF3, DF3, WF3, (d) Specimens NF, 


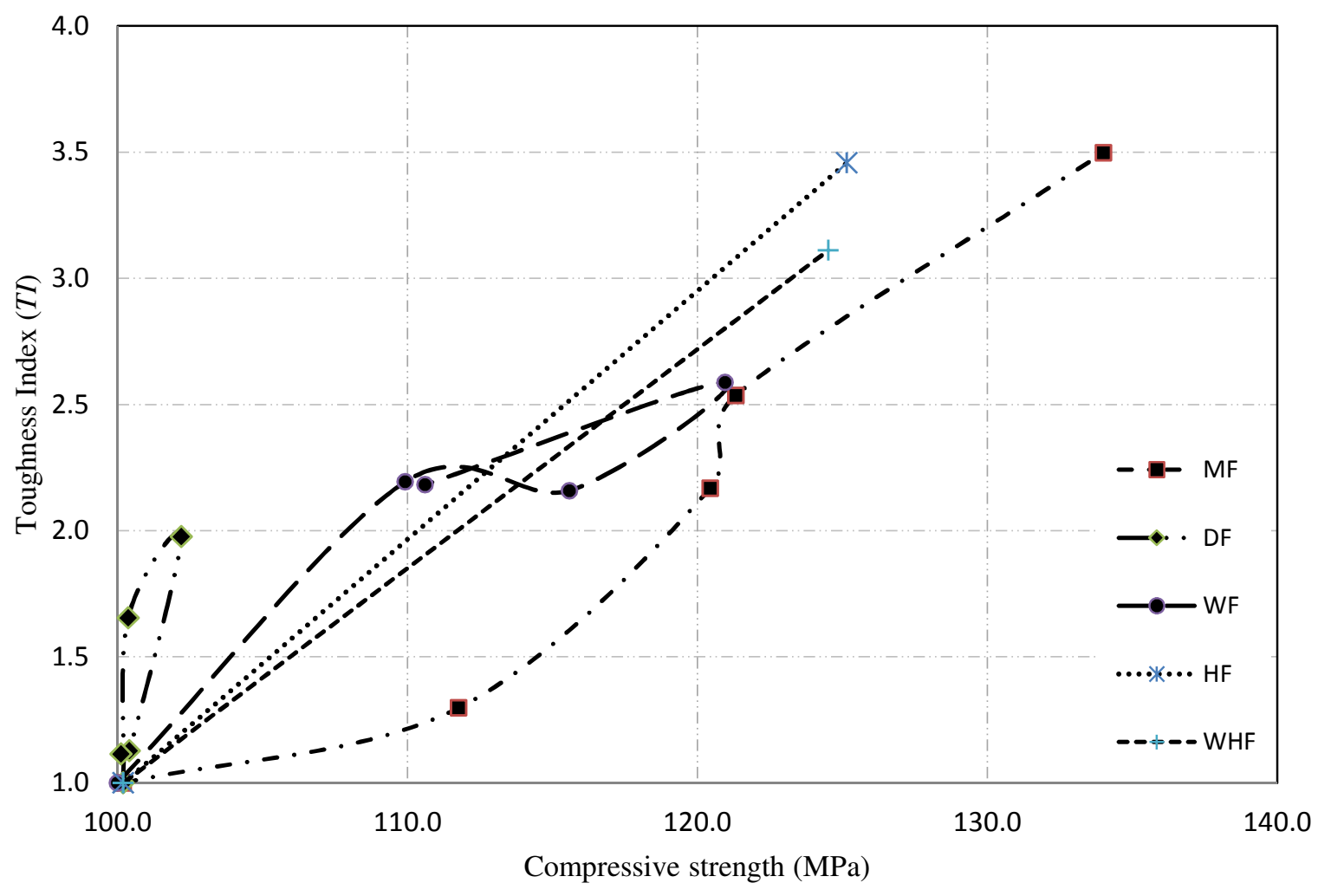

Fig. 14: The average Toughness Index vs the average compressive strength of RPC specimens.

957

958

959

960

961

962

963

964 


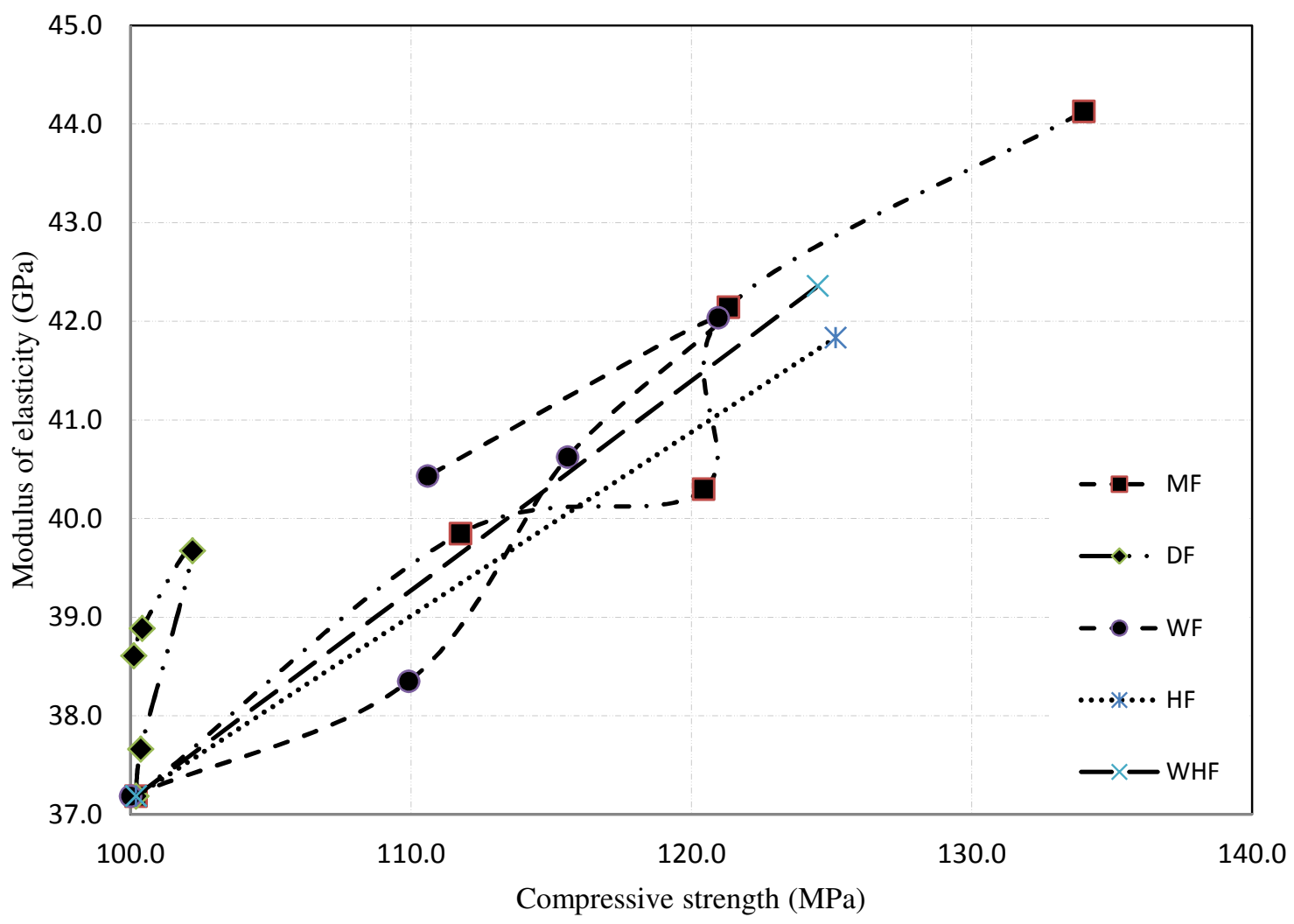

Fig. 15: The average modulus of elasticity vs the average compressive strength of RPC specimens. 


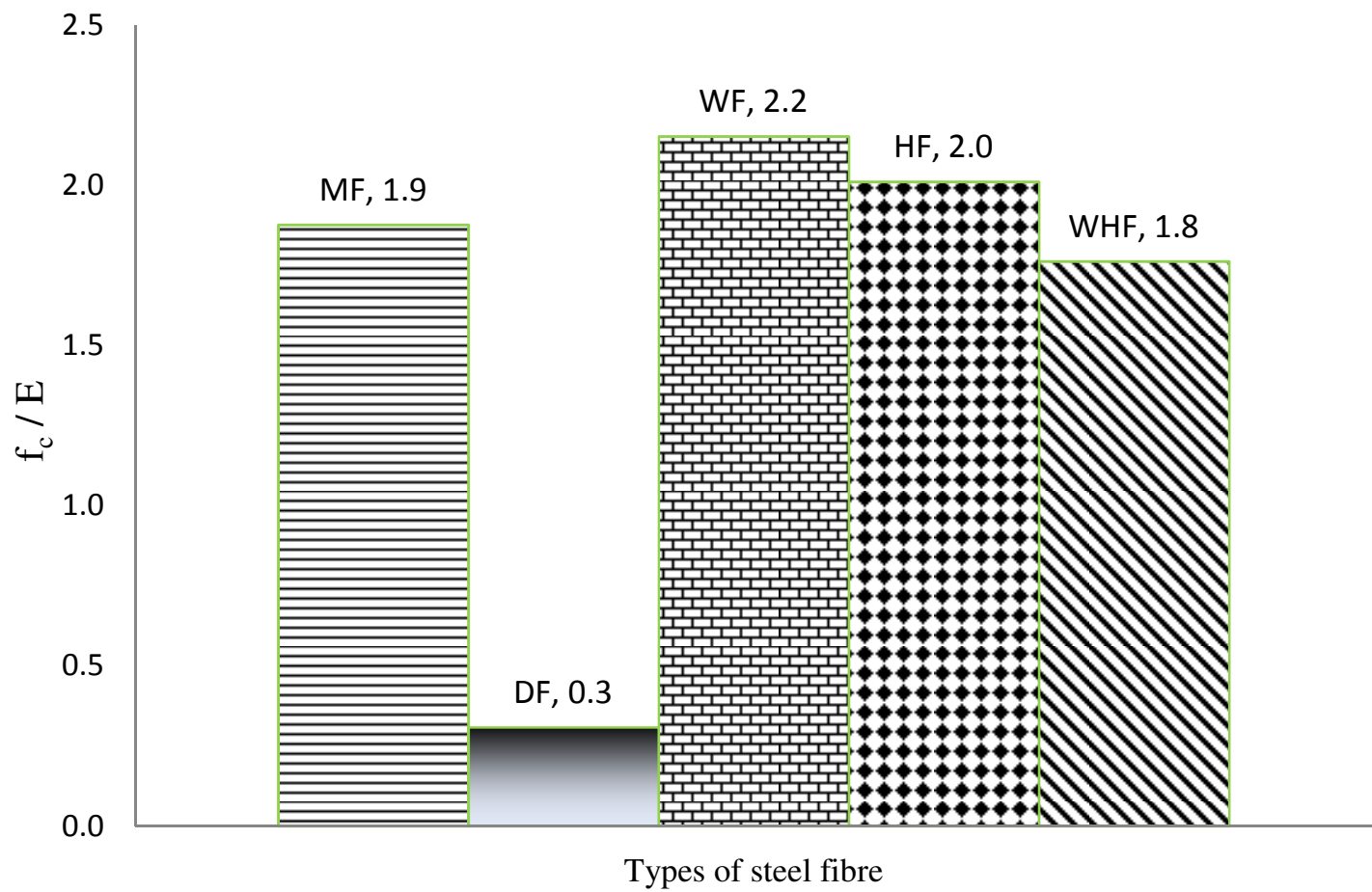

Fig. 16: The rate of increase in compressive strength to the modulus of elasticity of the tested 